Article

\title{
Improvement of Earthquake Risk Awareness and Seismic Literacy of Korean Citizens through Earthquake Vulnerability Map from the 2017 Pohang Earthquake, South Korea
}

\author{
Ju Han ${ }^{1}$, Arip Syaripudin Nur ${ }^{2}{ }^{\oplus}$, Mutiara Syifa ${ }^{3}$, Minsu Ha $^{3}$, Chang-Wook Lee ${ }^{2,3}$ and Ki-Young Lee ${ }^{3, *}$ \\ 1 Department of Home Economics Education, Kangwon National University, Gangwon-do, \\ Chuncheon-si 24341, Korea; zoz20202@kangwon.ac.kr \\ 2 Department of Smart Regional Innovation, Kangwon National University, Gangwon-do, \\ Chuncheon-si 24341, Korea; aripsyaripudin@kangwon.ac.kr (A.S.N.); cwlee@kangwon.ac.kr (C.-W.L.) \\ 3 Division of Science Education, Kangwon National University, Gangwon-do, Chuncheon-si 24341, Korea; \\ mutiarasyifa@kangwon.ac.kr (M.S.); msha@kangwon.ac.kr (M.H.) \\ * Correspondence: leeky@kangwon.ac.kr
}

check for updates

Citation: Han, J.; Nur, A.S.; Syifa, M.; Ha, M.; Lee, C.-W.; Lee, K.-Y. Improvement of Earthquake Risk Awareness and Seismic Literacy of Korean Citizens through Earthquake Vulnerability Map from the 2017 Pohang Earthquake, South Korea. Remote Sens. 2021, 13, 1365. https:// doi.org/10.3390/rs13071365

Academic Editor: Peter Hofmann

Received: 4 March 2021

Accepted: 27 March 2021

Published: 2 April 2021

Publisher's Note: MDPI stays neutral with regard to jurisdictional claims in published maps and institutional affiliations.

Copyright: (c) 2021 by the authors. Licensee MDPI, Basel, Switzerland. This article is an open access article distributed under the terms and conditions of the Creative Commons Attribution (CC BY) license (https:// creativecommons.org/licenses/by/ $4.0 /)$.

\begin{abstract}
Earthquake activities in and around the Korean Peninsula are relatively low in number and intensity compared with neighboring countries such as Japan and China. However, recent seismic activity caused great alarm and concern among citizens and government authorities, and uncovered the level of preparedness toward earthquake disasters. A survey has been conducted on 1256 participants to investigate the seismic literacy of Korean citizens, including seismic knowledge, awareness and management using a questionnaire of citizen earthquake literacy (CEL). The results declared that the citizens had low awareness and literacy, which means that they are not properly prepared for earthquake hazards. To develop an earthquake risk reduction plan and program efficiently and effectively, not only must it appropriately characterize the target audience, but also indicate high potential earthquake zones and potential earthquake damage. Therefore, this study mapped and analyzed the seismic vulnerability in southeast Korea using LogitBoost, logistic model tree (LMT), and logistic regression (LR) machine learning algorithms based on a building damage inventory map. The damaged buildings' locations were generated after the 2017 Pohang earthquake using the damage proxy map (DPM) method from the Sentinel-1 synthetic aperture radar (SAR) data. DPMs detected coherence loss, which indicates damaged buildings in urban areas in the Pohang earthquake and shows a good correlation with the Korea Meteorological Administration (KMA) report with modified Mercalli intensity (MMI) scale values of more than VII (seven). The damage locations were randomly divided into two datasets: $50 \%$ for training the vulnerability models and $50 \%$ for validating the models in terms of accuracy and reliability. Fifteen seismic-related factors were used to construct a model of each algorithm. Model validation based on the area under the receiver operating curve (AUC) was used to determine model accuracy. The AUC values of seismic vulnerability maps using the LogitBoost, LMT, and LR algorithms were 0.769, 0.851, and 0.749 , respectively. We suggest that earthquake preparedness efforts should focus on reconstruction, retrofitting, renovation, and seismic education in areas with high seismic vulnerability in South Korea. The results of this study are expected to be beneficial for engineers and policymakers aiming at developing disaster risk reduction plans, policies, and programs due to future seismic activity in South Korea.
\end{abstract}

Keywords: seismic vulnerability map; DPM method; Sentinel-1; machine learning; seismic literacy

\section{Introduction}

Earthquake activities in and around the Korean Peninsula are relatively low in number and intensity compared with neighboring countries such as Japan and China, because it is located within the Eurasian intracontinental region [1]. However, seismographs often 
record sudden occurrences of moderate earthquakes; historical documents show that several damaging earthquakes happened in the country [2], indicating that the Korean Peninsula is not completely safe from earthquake disasters.

On 15 November 2017, an $\mathrm{M}_{\mathrm{L}} 5.4$ earthquake occurred in Pohang, South Korea at 05:29:31 UTC [3], causing widespread damage in and around the city [4]. The earthquake was the second largest to occur in the Korean Peninsula since earthquake monitoring was initiated by the Korea Meteorological Administration (KMA) in 1978 [4,5]. In terms of the magnitude, the Pohang earthquake was not larger than the Gyeongju earthquake. However, the damage of the Pohang earthquake was much more than that of the Gyeongju earthquake. The Pohang earthquake caused more than USD $75 \mathrm{M}$ of indirect damage to over 57,000 structures and over USD $300 \mathrm{M}$ of total economic impact, as estimated by the Bank of Korea, injured 135 residents, and displaced more than 1700 people into emergency housing [6]. Meanwhile, the Gyeongju earthquake resulted in approximately USD 9.5 M in damage to 5368 properties, and 23 injured people [7]. More than 100 heritage buildings and monuments sustained damage from the earthquakes [8]. Twenty-one kilometers from Pohang, there is the Gyeongju Historic Area that was registered as a UNESCO World Cultural Heritage Site in November 2000, an area that embodies the time-honored history and culture of Gyeongju, the ancient capital of the Silla Kingdom (57 BC-935 AD). Some damage was found in this area, such as to Dabotap Pagoda (dislocated banister), Cheomseongdae Observatory (shifted and tilted), and Gyeongju Gyochon Traditional Village (cracked walls) [9]. Therefore, we need to conduct research about it.

Moreover, satellite images could detect surface deformation after the earthquake in Pohang, and therefore, for the first time, surface deformation measurements for an earthquake in Korea historically. A radar interferometry image was taken by the Sentinel1 satellite, highlighting a deformation of -5 to $5 \mathrm{~cm}$ (blue to red) that occurred near Pohang city center. This image was obtained from a two-pass interferogram created using GAMMA software [10]; in this process, two synthetic aperture radar (SAR) images (4 and 16 November 2017) were co-registered to form an interferometric pair, which were then cropped to the area of interest. Topographic interferometric synthetic aperture radar (InSAR) images were then produced through interferogram generation. These images were derived from global 1 arcsecond Shuttle Radar Topography Mission (SRTM) data (30 m resolution), followed by topographic phase removal and differential synthetic aperture radar interferometry (DInSAR) phase generation, leaving only the deformation phase image [11]. A phase unwrapping procedure was then applied to generate an unwrapped DInSAR image, for conversion into displacement values $(\mathrm{cm})$. Considering the uniqueness of this earthquake, we choose Pohang earthquake as our study case.

Additionally, we also need to know citizens' risk awareness about earthquakes in Korea as they had never experienced or felt the degree of natural hazard caused by the Pohang earthquake directly before. However, many people were not aware of earthquakes risk from the survey data. A survey was conducted with 1256 Korean citizens during spring 2020. Figure 1 shows the survey results that only $6 \%$ of the participants were aware that where their live is "absolutely not at all" safe from earthquakes, $29 \%$ of the participants thought "hardly not", 42\% thought "normal", 20\% thought "to some extent", and 3\% thought they were "absolutely" safe from earthquakes. These results are an important warning sign for regulators and authorities, given the recent earthquakes that caused great human and material losses. 


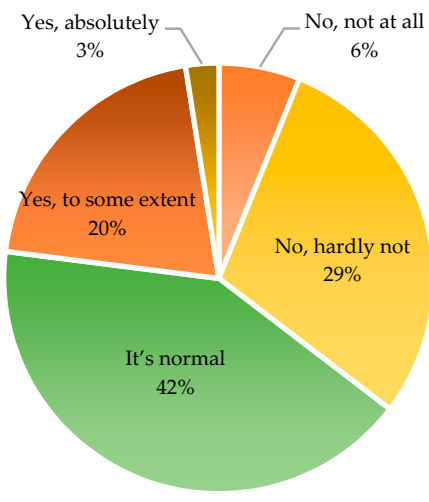

I think the place where I live is safe from earthquakes

Figure 1. Chart of earthquake risk awareness of Korean citizens.

However, a small number of people in the earthquake area (close distance) were aware of the extreme fear and danger of earthquakes compared to the majority of people according to the survey results. Figure 2 shows that people who live near the epicenter of the Pohang earthquake have higher awareness of earthquakes because they were directly affected by the damage from the Pohang earthquake. Meanwhile, people who live far from the epicenter, such as people living in Seoul, have a lower awareness level of earthquakes because they only felt a slight shock from the Pohang earthquake, which was not fatal. Therefore, we need to inform many people of the dangers caused by such an earthquake, and when earthquakes occur in another area in the future, we need to be able to recognize the earthquake and respond to it.

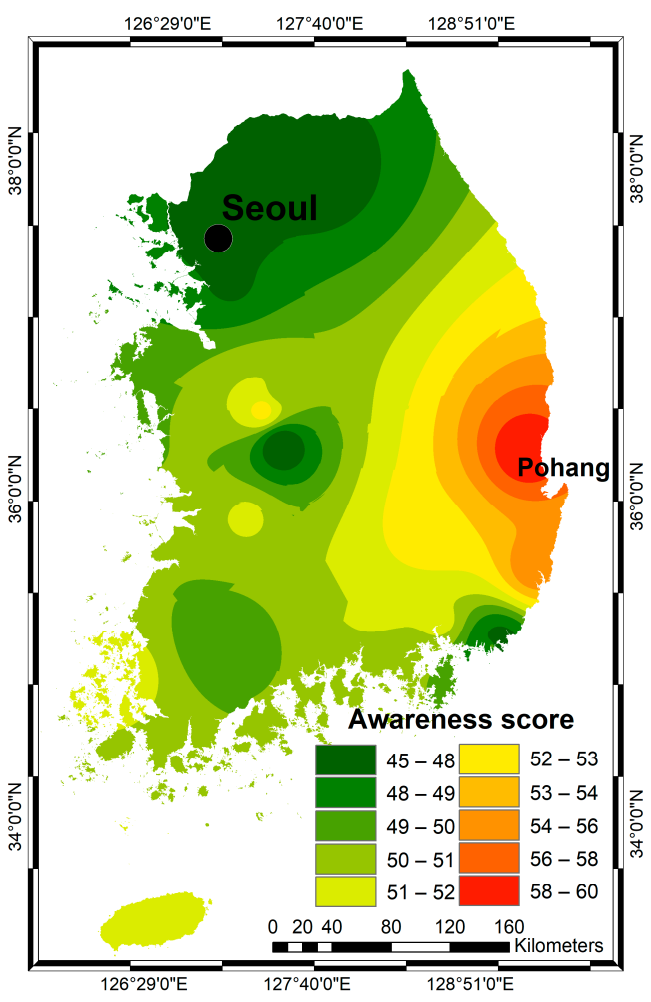

Figure 2. Map of citizens' awareness risk awareness score throughout Korea.

To reduce the effects of earthquake disasters and develop an earthquake risk reduction plan and program efficiently and effectively, not only is performing sustainable preparation, such as seismic literacy of citizens, necessary, but so is indicating high potential earthquake zones and potential earthquake damage by producing seismic vulnerability maps. Seismic vulnerability assessment involves the comprehensive evaluation of factors that affect risks 
associated with earthquakes within predefined areas. Urban areas are at higher risk of seismic disasters than outlying areas due to their higher building and infrastructure density and larger population. Therefore, in assessing seismic vulnerability, it is essential to select suitable influential factors and methods for the area of interest. Several methodologies have been applied for seismic vulnerability assessment and mapping during the past few decades [7,12-15].

Seismic vulnerability assessment studies commonly analyze case studies using a combination of multicriteria decision making (MCDM) and geographic information system (GIS) approaches $[12,13,16,17]$. Among these, the analytical hierarchy process (AHP) is one of the most widely known MCDM methodologies; it stratifies and quantifies the importance of each applied influential factor to determine its relative importance, and assesses vulnerability by applying weights to all factors $[12,16,18]$. However, this method can be subjective because the opinion of the researcher can affect the weight assignment process; therefore, it is somewhat unsuitable for objective assessment. To address this problem, recent studies have applied hybrid models that combine various methodologies $[14,19]$.

Many recent studies related to seismic vulnerability assessment and mapping have been conducted using machine learning techniques [12,16,18-21]. For example, Han et al. (2019) [20] used a logistic regression (LR) model and applied the support vector machine (SVM) methodology to four kernel models (linear, polynomial, radial basis function, and sigmoid) to derive a suitable model for seismic vulnerability assessment; this study was notable in that the results of several seismic vulnerability models were compared analytically; such analyses are rarely conducted in this field, despite the broad application of machine learning techniques in recent years.

Providing training data plays an important role in the accuracy of the vulnerability map. Here, we used the damage proxy map (DPM) method to extract a building damage map for training and testing datasets. The DPM method is part of an ongoing collaborative effort between the Jet Propulsion Laboratory (JPL) and the California Institute of Technology, called the Advanced Rapid Imaging and Analysis (ARIA) project. The DPM method, using synthetic aperture radar (SAR) satellite data, has been shown to be useful for damage mapping following an earthquake and other natural disaster events, including the 2015 MW 7.8 Gorkha, Nepal earthquake using COSMO-SkyMed and ALOS-2 satellites [20], the 2019 typhoon Hagibis, Japan using Sentinel-1 satellites [21], the 2019 MW 7.1 Ridgecrest earthquake in California using Sentinel-1 satellites [22], and the 2014 eruption of Kelud volcano (Indonesia) using COSMO SkyMED satellites [23].

This study aims to improve the risk awareness and seismic literacy of Korean citizens through an earthquake vulnerability map of all buildings in southeast Korea. To produce the earthquake vulnerability map, we generated a damage proxy map (DPM) after the 2017 Pohang earthquake from the Sentinel-1 SAR dataset as a dependent variable, then applied machine learning to construct models using 15 seismic-related factors as independent variables. Model performances were verified using a receiver operating characteristic (ROC) curve. Finally, dangerous and safe areas were identified in southeast Korea by creating maps based on the model with the highest accuracy for each methodology, and the result were assessed. The results of this study should improve citizen earthquake risk awareness and seismic literacy, especially in high seismic vulnerability areas, and facilitate the construction of seismic vulnerability models that will be useful to reduce future losses due to earthquakes in South Korea.

\section{Materials and Methods}

\subsection{Study Area}

The study area covers three metropolitan cities; Busan, Daegu, and Ulsan, and two provinces; Geyongsangbuk and Gyeongsangnam, surrounding the epicenter of the Pohang earthquake. For simplicity, we refer to it as southeast Korea. The blue line in Figure 3 shows the border of the study area. In total, southeast Korea is home to 12,961,687 people and has an area of $32,285 \mathrm{~km}^{2}$ [24]. Within the total area, urban areas account for $5.49 \%$, followed 
by agriculture at $21.88 \%$, forestry $(66.71 \%)$, and other areas $(5.92 \%)$. The proportions of males and females in these areas are $50.21 \%$ and $49.79 \%$, respectively [25].

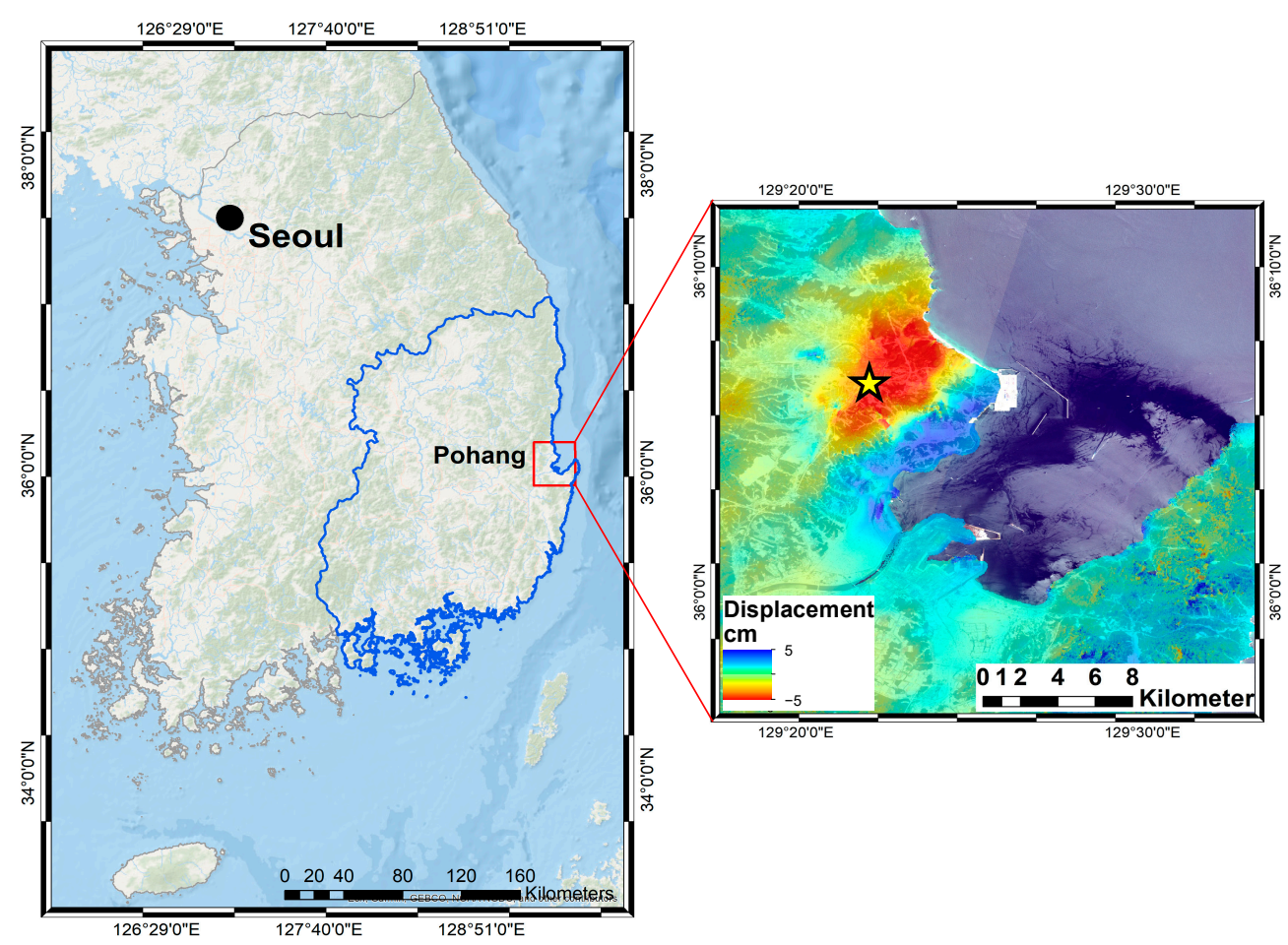

Figure 3. Study area of this study, indicated by a blue line. Location of the 2017 Pohang earthquake and surface deformation generated from Sentinel-1 synthetic aperture radar (SAR) data acquired on 4 and 16 November 2017.

The study area was chosen considering the high seismic activity in these areas. A series of aftershocks of the Pohang earthquake was observed to have occurred with a magnitude of 3.0 or more until 31 May 2018. A magnitude of 4.3 occurred near the epicenter, $2 \mathrm{~h}$ after the mainshock, and a magnitude 4.6 earthquake occurred $4 \mathrm{~km}$ to the southwest at around 20:03:04 UTC on 11 February 2018 [26]. One year prior to the Pohang earthquake, an $\mathrm{M}_{\mathrm{L}} 5.8$ earthquake shocked Gyeongju at 11:32:55 UTC on 12 September 2016. The epicenter was $8.7 \mathrm{~km}$ from the south of the city and $15 \mathrm{~km}$ beneath the surface [27]. The Gyeongju earthquake was just $40 \mathrm{~km}$ from the site of the Pohang earthquake. The Gyeongju earthquake was accompanied by 600 aftershocks, including an $\mathrm{M}_{\mathrm{L}} 5.1$ foreshock that occurred near the mainshock at 10:44:32 UTC [28]. In 2018, 115 earthquakes with magnitudes of more than 2 occurred in the Korean Peninsula; among these, 36 earthquakes (31.13\%) occurred in southeast Korea [29]. In 2019, 957 earthquakes with a magnitude of less than 2.0 occurred in the Korean Peninsula; among these, 294 earthquakes (30.72\%) occurred in southeast Korea [30]. Among the 88 earthquakes of magnitude 2.0 or higher, $23(26.17 \%)$ occurred in the same area.

The Korean Peninsula lies at the eastern margin of the Eurasian Plate. About 30-15 million years ago, north-northeast (NNE)-striking strike-slip faults and NNE- to NE-striking normal faults settled predominantly in southeastern Korea and adjacent offshore areas when the East Sea opened in the early to middle Tertiary as a back-arc basin; smaller-scale coetaneous basins also formed, including the Pohang Basin. Although this region is about $400-500 \mathrm{~km}$ in length, its seismicity is affected by complex interactions of the Indo-Australian and Eurasian plates, as well as by subduction of Philippine Sea plates beneath the Japan and Ryuku trenches [31]. Several faults are distributed within the study area, including Dongrae, Moryang, Miryang, Ulsan, Wangsan, and Yangsan [32]. Due to seismic history and geographic characteristics, the probability of earthquake occurrence in southeast Korea is considered relatively high, and secondary damage in the event of an earthquake with a medium or higher magnitude constitutes 
an unusually high risk. Therefore, sustainable preparation and management planning for such events is required.

\subsection{SAR Datasets}

A building damage inventory map for producing the seismic vulnerability map in southeast Korea was generated using Sentinel-1 synthetic aperture radar (SAR) C-band data ( $5.5 \mathrm{~cm}$ wavelength) provided by the European Space Agency (ESA). Pohang is located in between two frames (470 and 475), path 61 of the Sentinel-1 imagery; therefore, we obtained six Sentinel-1 single look complex (SLC) images with vertical transmission and vertical return (VV) polarization for the Pohang earthquake, with four scenes prior to the event on 23 October 2017, and 4 November 2017, and two scenes after the event on 16 November 2017. Furthermore, we needed to merge the scenes before processing. The images were co-registered, with the 4 November 2017 scenes as a reference.

\subsection{Damage Proxy Map (DPM)}

DPMs generated from the comparison of pre- and co-event SAR images can help identify damage caused by earthquakes using remote sensing imagery [20]. The method relies on the reduction in the coherence of the radar echoes between satellite-based SAR images taken before and after the earthquake to identify anomalous changes in ground surface properties. Coherence measures the change in radar backscatter from the ground, a proxy for the ground-surface property changes. A low coherence implies a large change to the ground surface that reflected the SAR radiation [33]. Changes can be caused by damage to the ground itself or damage to structures.

The process started with image co-registration, with the 4 November 2017 scenes as a reference. This co-registration process was done with sub-pixel accuracy to match scenes to one another. We used the complex pixel value, c, of the pre-processed SLCs for the change detection analysis, where damage is inferred from loss of coherence or decorrelation between SAR images [20]. We computed the pre-and co-event interferometric coherences, $\gamma$ (Equation (1)), from a pair of SLCs before the event and another pair spanning across the event, respectively [21].

$$
\gamma=\frac{\left|\left\langle\mathrm{c}_{1} \mathrm{c}_{2}^{*}\right\rangle\right|}{\sqrt{\left\langle\mathrm{c}_{1} \mathrm{c}_{1}^{*}\right\rangle\left\langle\mathrm{c}_{1} \mathrm{c}_{2}^{*}\right\rangle}}, 0 \leq \gamma \leq 1
$$

where $c_{1}$ and $c_{2}$ are complex pixel values of two co-registered SAR images and * denotes the complex conjugate. The resulting coherence ranges from 0 (incoherent) to 1 (coherent). The coherence is equal to 1 if the observation is identical in the two images because of the stable object-like buildings in the scene. The pre-event coherence represented change unrelated to the event and was assumed to be the background value. Then, we obtained a coherence difference (COD) by subtracting $\gamma_{\text {pre-event }}$ from $\gamma_{\text {co-event }}$. Therefore, the process could generate a COD ranging from -1 to 1 . A negative $\mathrm{COD}$ (or coherence gain) usually indicates surface changes occurring between the pre-event scenes and is associated with changes not related to the event. Coherence gain could happen in an agricultural area when the fields are full of crops. Then, when harvested during the period time of the pre-event interferometric pair, the area has low coherence. After harvesting, leaving an empty field, the area has a greater coherence in the co-event interferometric pair $\left(\gamma_{\text {co-event }}>\gamma_{\text {pre-event }}\right)$, so a negative COD is obtained. A positive COD (or coherence loss) indicates surface changes between the co-event scenes spanning the events, such as major damage to a building significantly that increases the interferometric phase variance, causing a decrease in coherence. Hence, the loss of coherence is most effective for detecting damage in built-up areas caused by earthquake. However, COD is generally less effective and less reliable in vegetated areas where coherence changes may be random. Therefore, this study focused on a DPM in urban, built-up areas as changes can be detected easily in SAR imagery. A greater loss in coherence generally correlates with greater severity of the change, such as a fully collapsed building, causing more significant coherence loss than partial collapse [21]. 
The threshold for significant coherence loss can be chosen by comparing observed coherence changes with reported damage and areas in which it is known that no damage occurred. Yun et al. (2015) compared a DPM with a National Geospatial-Intelligence Agency (NGA) analysis and the United Nations Operational Satellite Application Programme (UNOSAT) damage assessment map. Tay et al. (2020) used high-resolution aerial imagery from the Geospatial Information Authority of Japan (GSI). Here, coherence loss thresholds for DPMs were chosen by considering the damaged area from the Korea Meteorological Administration (KMA) report of the Pohang earthquake [34].

\subsection{Selection of Seismic-Related Factors}

We selected factors affecting seismic vulnerability based on the result of previous studies $[7,14,15,17]$. The factors affecting the seismic vulnerability were prepared based on five main indicators, which were geotechnical, physical, structural, social, and capacity; we selected a total of 15 factors corresponding to these categories. Geotechnical factors included slope and altitude; physical factors included peak ground acceleration (PGA), epicenter distance, and fault distance; structural factors included land use, construction materials, building density, and building height; social factors included elderly population ( $\geq 65$ years), child population ( $<15$ years), and population density; and capacity factors included distances from hospitals, fire stations, and police stations. The factors were organized into raster-based spatial databases ( $30 \mathrm{~m}$ spatial resolution) and were reclassified using the quantile method to identify and analyze the effect of each class. The data used in this present study are shown in Figure 4.

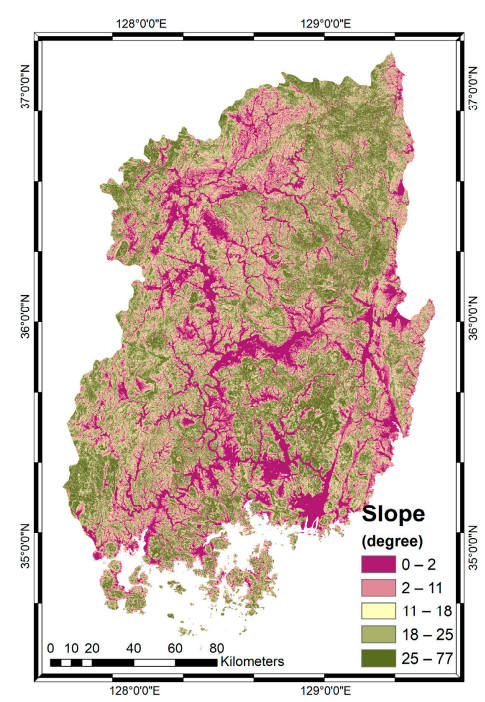

(a)

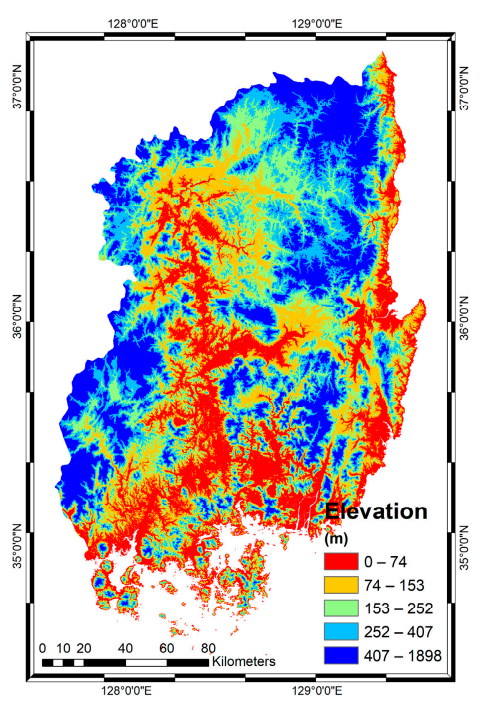

(b)

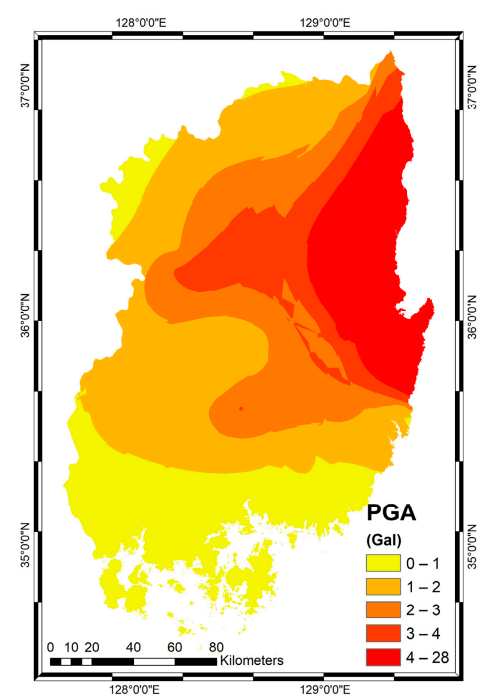

(c)

Figure 4. Cont. 


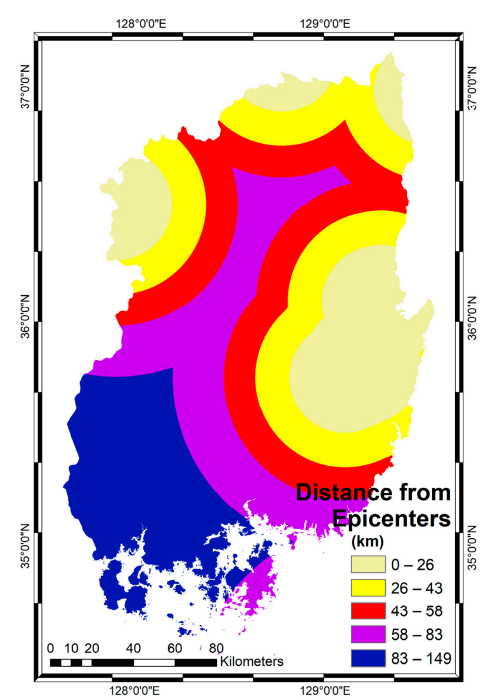

(d)

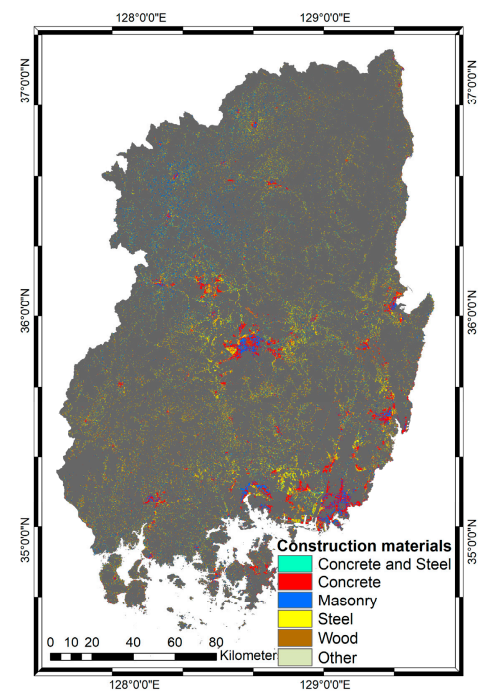

(g)

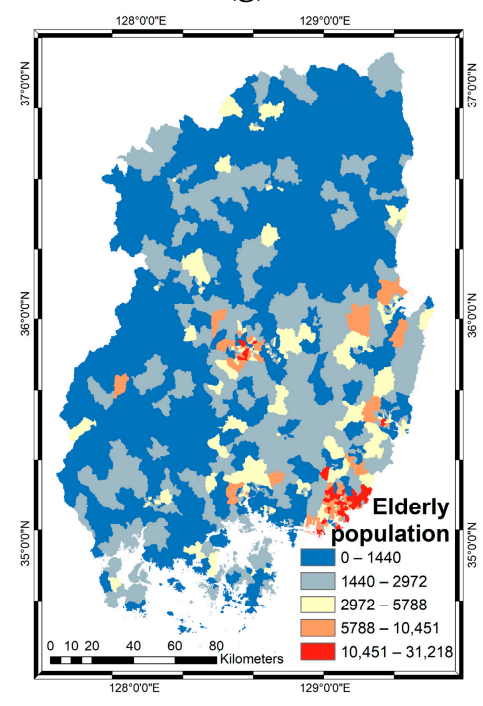

(j)

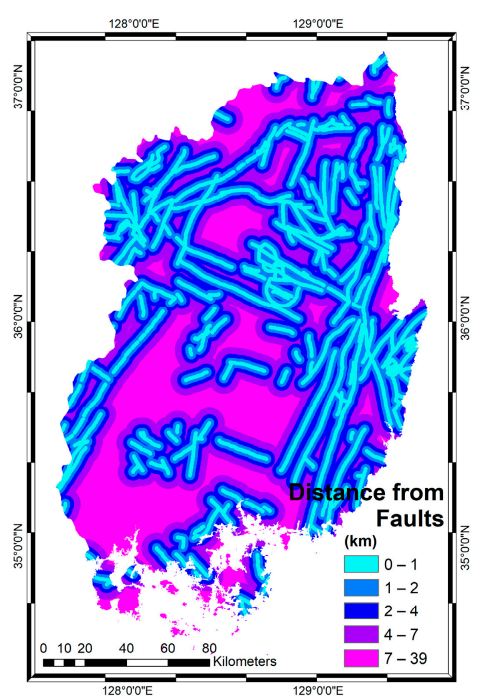

(e)

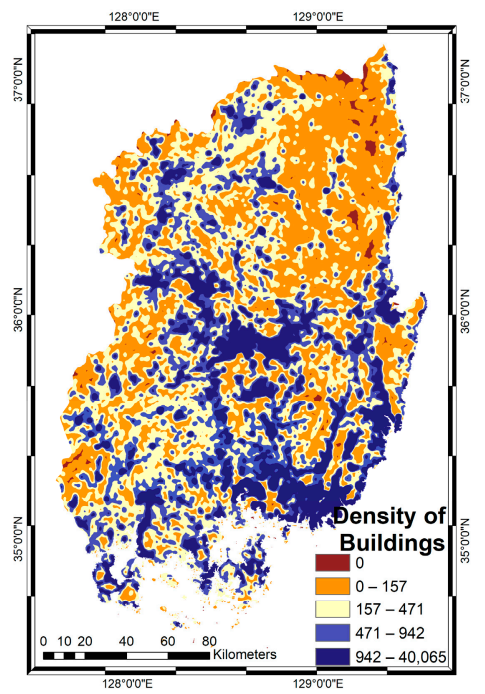

(h)

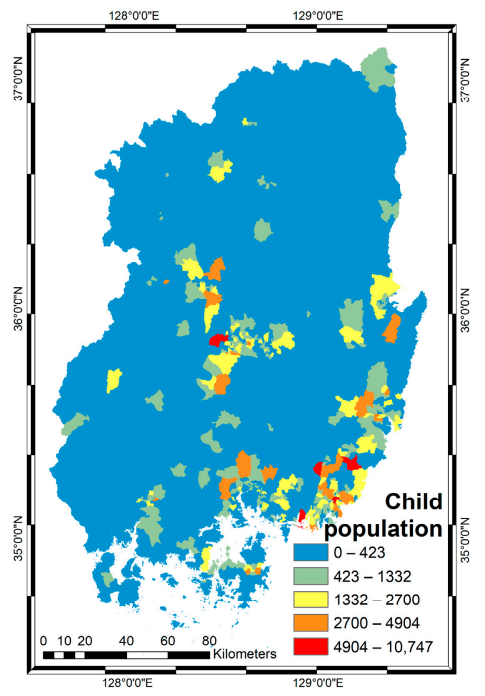

(k)

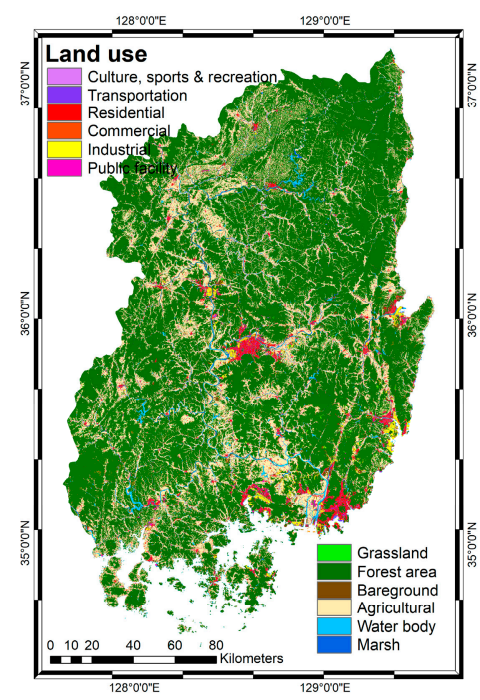

(f)

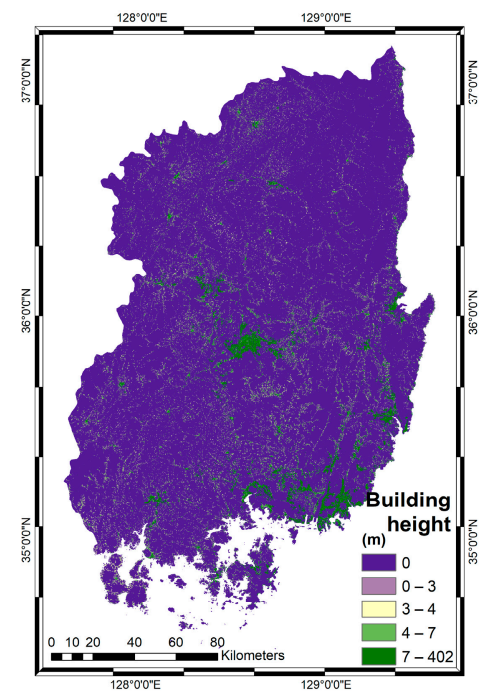

(i)

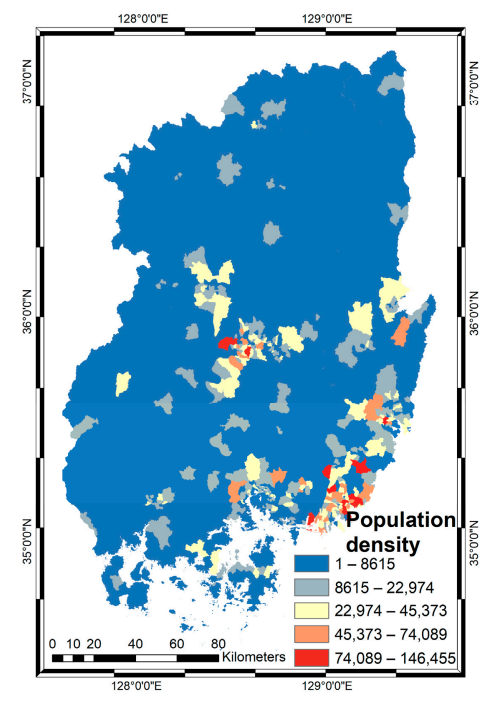

(1)

Figure 4. Cont. 


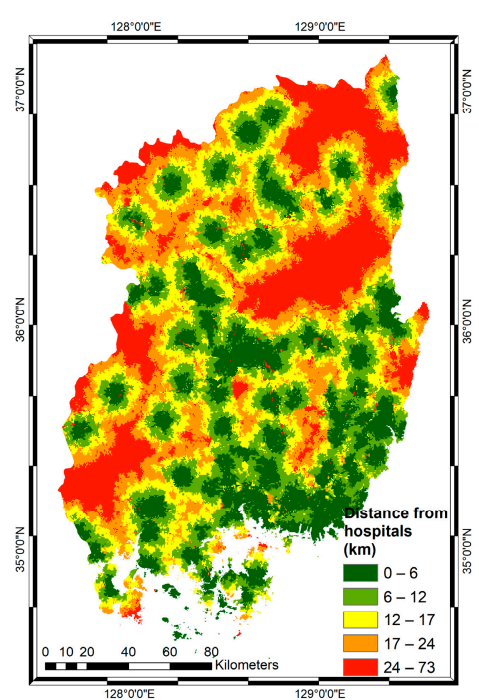

(m)

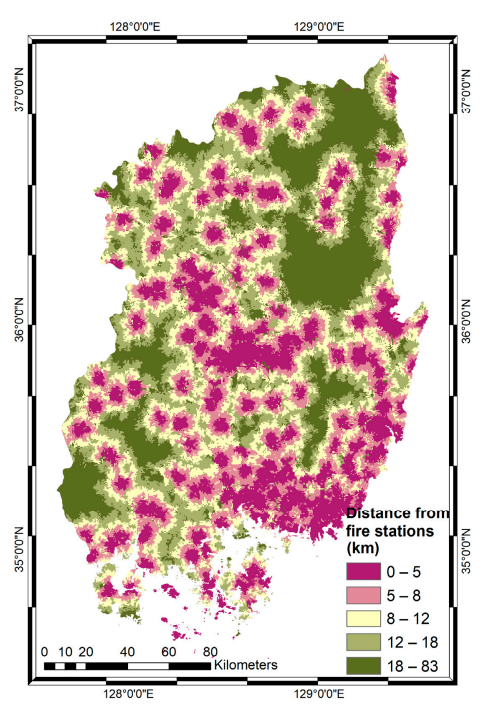

(n)

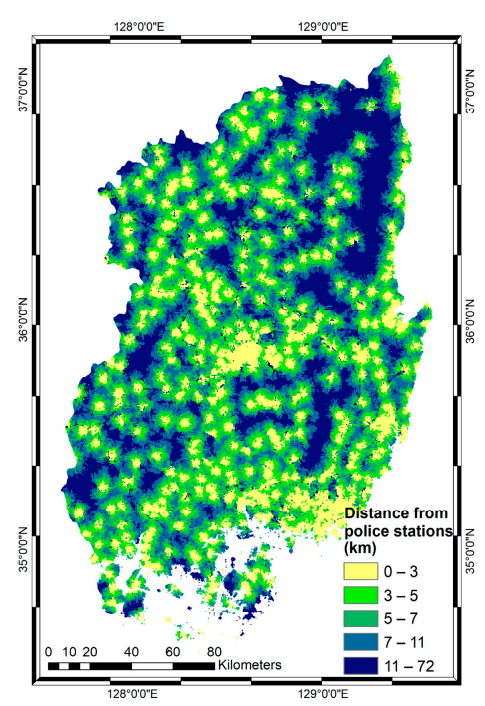

(o)

Figure 4. Factors related to seismic vulnerability: (a) slope, (b) elevation, (c) peak ground acceleration (PGA), (d) distance from epicenters, (e) distance from faults, (f) land use, (g) construction materials, (h) density of buildings, (i) building height, (j) elderly population, (k) child population, (1) population density, $(\mathbf{m})$ distance from hospitals, (n) distance from fire stations, and (o) distance from police stations.

Slope and elevation were extracted from a digital elevation model (DEM) of the Shuttle Radar Topography Mission (SRTM) using basic terrain analysis tools. Slope and elevation are factors affecting the vulnerability of urban environments to earthquakes [14,35]. Degradation in terrain with steep topography, especially at the top of hills and peaks, is greatly enhanced. According to construction standards, a slope of 5 to $9 \%$ is suitable for urbanization [16]. The highs and lows of elevation in each area are highly correlated with landslide susceptibility in each area [36]. Therefore, because of the amount of erosion and its relation to human activity, the higher the altitude of an area, the greater the seismic vulnerability. Figure $4 \mathrm{a}$, b shows the slope and elevation maps of southeast Korea, respectively.

Peak ground acceleration (PGA) (Figure 4c) is the degree to which the ground shakes at the Earth's surface and is related to the amount of fault activity [18]. In this study, raw data from the Korea Institute of Geoscience and Mineral Resources (KIGAM) were converted to acceleration data and interpolated throughout southeast Korea $[27,37]$. The epicenter, or location where an earthquake occurs, is an important factor related to earthquake occurrence; the level of damage is different depending on the ground condition or the structure of the fault plane, on which the greatest damage often occurs at the epicenter. Therefore, we used distance data from earthquake epicenters (Figure 4d) with a magnitude over 4 from 1978 to 2020, including the 2016 Gyeongju earthquake and the 2017 Pohang earthquake. The epicenter locations were acquired from the United States Geological Survey (USGS). The faults are forms of tectonic factors whose presence or absence can be examined in relation to the seismic hazard of different areas. Fault distance (Figure 4e) plays a key role in vulnerability to earthquake hazards, as proximity to the fault causes high seismic risk and damage, and distance from it will reduce the risk and consequently provide higher resilience [16].

Anti-seismic design in South Korea was introduced in 1988, and it is mandatory only for buildings that are three stories or higher [38]. As of November 2016, 29.9\% of residential buildings and $23.7 \%$ of non-residential buildings in Seoul were designed to be anti-seismic. As there is no guarantee that future earthquakes will not exceed the magnitude of the Gyeongju earthquake, most buildings in South Korea are considered highly vulnerable. To assess their vulnerability, we identified four structural factors of seismic vulnerability: land use, construction materials, building density, and building height, depicted in Figure $4 \mathrm{f}-\mathrm{i}$, respectively $[7,17]$. The greater the number of floors of a building, despite its quality, the 
greater the vulnerability. The number of floors in the building, if not in accordance with safety principles, will definitely increase the damage [39]. Even if the height is treated with due diligence and calculations, it is difficult for the evacuation of buildings, and to search for and rescue people. Obviously, structures of high strength and standard materials have good earthquake safety [40]. Proper deployment of land uses on the basis of urban planning principles, such as proper accessibility, proper distance from the biological hotspots, safety, comfort, and utility can substantially reduce the amount of vulnerability, injury, and economic damage [41].

Increasing population growth, population density, and poor distribution of services and infrastructure pose risks to society [42]. In recent earthquakes around the world, it can be said that most of the damage is to humans and with the increase in population, it is predicted that in the future, the mortality rate will be higher. The earthquake hazard coefficient in urban centers is also more complex and riskier due to urbanization without planning and development [43]. In events such as earthquakes, everyone in the community is vulnerable, but older people and children are the most vulnerable groups in a community and more attention is needed to minimize pain and injury [44]. Children do not tolerate disruption well and older people are psychologically fragile because of their disrupted life rhythms. The elderly population, child population, and population density in southeast Korea are presented in Figure 4j-1, respectively.

We identified the locations of social infrastructure facilities that offer aid in the event of an earthquake, and of hazardous facilities that have the potential to cause huge damage. The degree of accessibility following a disaster was analyzed by considering the physical distances to three factors, including social infrastructure facilities (hospital, police station, and fire station). Distance from a hospital (Figure $4 \mathrm{~m}$ ) and access to health services such as hospitals play a key role in controlling post-emergency complications and providing earthquake rescue and hospitalization services. Proper and quick access to medical facilities will increase earthquake resilience [45]. Distance from a fire station (Figure 4n) and access to police stations (Figure 4o) through the communication networks will speed up rescue operations and service the injured. As such, the greater the distance from fire stations and police stations, the greater the vulnerability [46].

\subsection{Machine Learning}

To map seismic vulnerability using a machine learning algorithm, several steps must be performed. First, the spatial relationships between the damaged buildings from the DPM and related factors (geotechnical, physical, structural, social, and capacity indicators) are calculated using the frequency ratio (FR) method. In this research, we analyzed the spatial relationship between damaged buildings' locations (1623 cells) and 15 factors related to seismic vulnerability, based on the FR value of each factor. When the ratio is greater than 1, this denotes that the class in each factor has a closer relationship with seismic vulnerability [47]. In the case that each factor has a less close relationship with seismic vulnerability, the ratio is less than 1 . The FR for each factor was calculated by Equation (2) [48].

$$
\mathrm{FR}=\frac{\% \text { of class of related factor }}{\% \text { of total area }}
$$

To apply the machine learning algorithm, we used the 1623 cells of damaged buildings generated from the DPM method. Among these cells, 50\% (812) were used as a training dataset and $50 \%$ (811) were used as a test dataset. We extracted the same number of cells corresponding to undamaged buildings. All cells were randomly sampled and generating models and the accuracy of each model was done based on training (1624) and test datasets (1622). Several seismic-related maps, including geological maps, were produced at a $30 \mathrm{~m}$ resolution. Then, all data were classified as categorical or continuous. Continuous variables include the slope, elevation, PGA, distance from epicenters, distance from faults, building density, building height, child population, elderly population, population density, distance 
from hospitals, distance from police stations, and distance from fire stations. Categorical variables include construction materials and land use.

Model validation was carried out through ROC curve analysis of the testing dataset $(50 \%)$. Receiver operating characteristic (ROC) curve analysis, as an index of model performance, is commonly used to assess predictive accuracy [49]. To quantitatively determine the accuracy of the model verification, the area under the curve (AUC) of the ROC curve is calculated for the total area and correct predictive accuracy is obtained. AUC values range between 0.5 and 1 ; higher values indicate more reliable algorithm performance. The workflow of the seismic vulnerability mapping carried out in this study is provided in Figure 5.

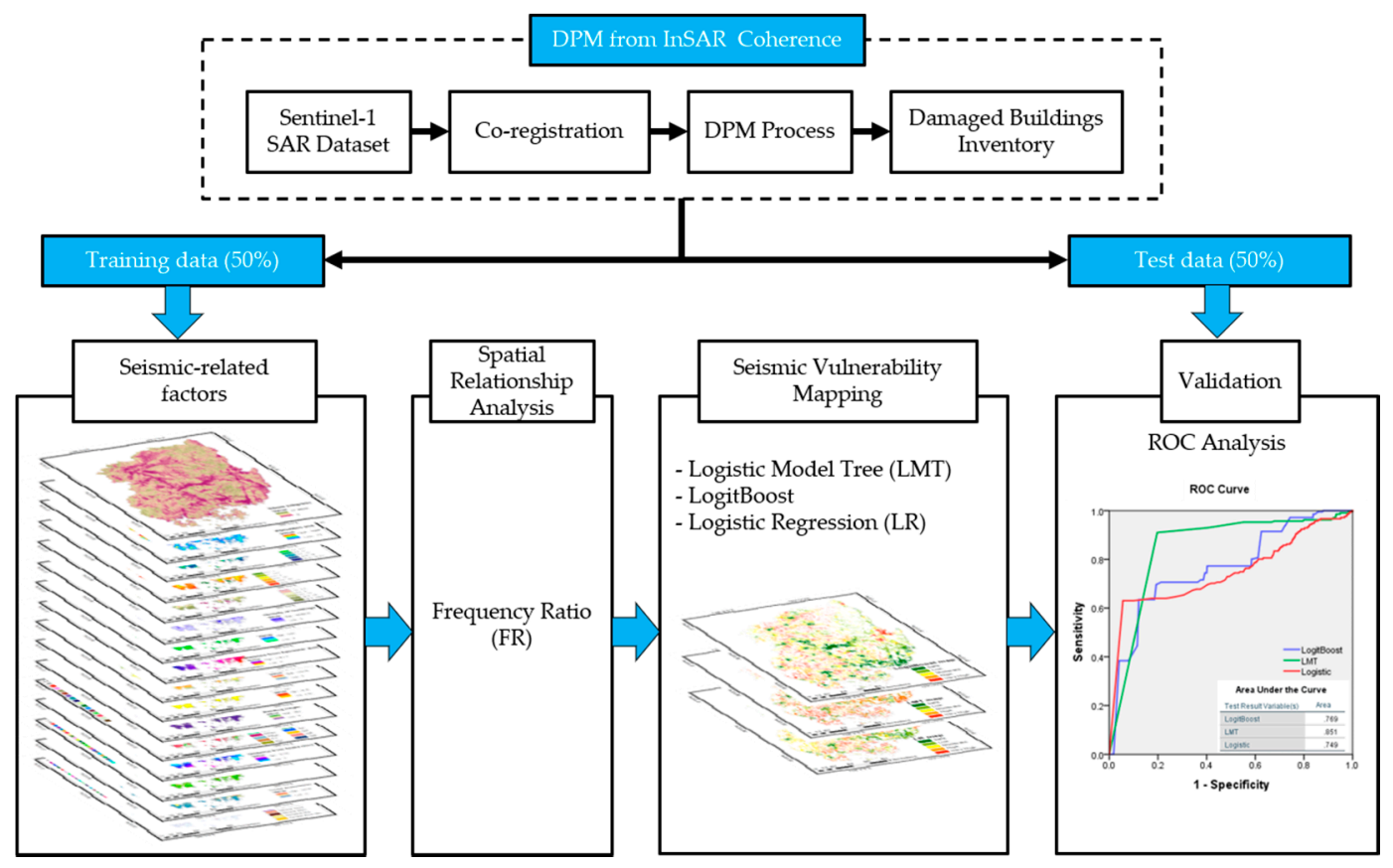

Figure 5. Workflow of seismic vulnerability mapping. Abbreviations: DPM, damage proxy map; InSAR, interferometric synthetic aperture radar; ROC, receiver operating characteristic.

\subsubsection{LogitBoost}

LogitBoost is a boosting algorithm developed by Friedman et al. [50] to reduce bias and variance. The LogitBoost algorithm was modified from AdaBoost, which was the commonly used boosting method for handling noisy data that executes additive logistic regression with least-square fits for individual classes. LogitBoost reduces training errors and enhances classification accuracy by using additive logistic regression for classification with a base-learning regression scheme and an ability to perform multiclass classification. The damaged building inventory map was divided into two classes: damaged buildings and undamaged buildings, using Equation (3):

$$
\operatorname{Lc}(\mathrm{c})=\sum_{\mathrm{i}=1}^{\mathrm{D}} \beta_{\mathrm{i}} \mathrm{x}_{\mathrm{i}}+\beta_{0}
$$

where $\mathrm{D}$ is the number of building damage-dependent factors and $\beta_{\mathrm{i}}$ is the coefficient of the $\mathrm{i}$-th component within input vector $\mathrm{x}$. Probabilities were constructed using the linear logistic regression method with Equation (4):

$$
\mathrm{P}\left(\frac{\mathrm{C}}{\mathrm{x}}\right)=\exp (\mathrm{Lc}(\mathrm{x})) / \sum_{\mathrm{C}^{\prime}=1}^{\mathrm{C}} \exp \left(\mathrm{Lc}^{\prime}(\mathrm{x})\right)
$$


where $C$ is the number of classes and the least-square fit $\operatorname{Lc}(x)$ is resolved such that $\sum_{C=1} L_{C}^{C}(x)=0$ to set up the least number of instances per node of the logistic model trees.

\subsubsection{Logistic Model Tree (LMT)}

The logistic model tree combines the C4.5 algorithm [51] and logistic regression (LR) functions. The information gain ratio (IGR) technique is applied to split the tree into nodes and leaves, and the LogitBoost algorithm [52] is used to fit the logistic regression functions at a tree node. The C 4.5 algorithm uses the entropy technique for feature selection because it is the fastest method for providing reliable classification accuracy [53]. The over-fitting problem, which is an important challenge in LMT modeling, is overcome using the CART algorithm, which prunes the tree for modeling the training dataset [54]. The IGR can be formulated using Equation (5):

$$
\text { Gain ratio }(\mathrm{A})=\frac{\text { gain }(\mathrm{A})}{\text { split info }(\mathrm{A})}
$$

where gain (A) is the information after attribute $A$ is selected as a test for classification of the training samples and split info (A) is the information generated when $x$ training samples are categorized into $n$ subsets [51]. In the next step, the LogitBoost algorithm performs additive logistic regression with least-squares fit for each class $\mathrm{Ci}$ (damaged or undamaged building) according to Equation (6) [55]:

$$
\mathrm{L}_{\mathrm{c}}(\mathrm{x})=\sum_{\mathrm{i}=1}^{\mathrm{CF}} \alpha_{\mathrm{i}} \mathrm{x}_{\mathrm{i}}+\alpha_{0}
$$

where $\mathrm{L}_{\mathrm{c}}(\mathrm{x})$ is the least-squares fit and CF and $\alpha_{\mathrm{i}}$ are, respectively, the number of seismicrelated factors and the coefficient of the i-th element of vector $\mathrm{x}$. The a posteriori probabilities in the leaves of the LMT are calculated using the linear logistic regression model with Equation (7) [52]:

$$
\mathrm{p}(\mathrm{c} \mid \mathrm{x})=\frac{\exp \left(\mathrm{L}_{\mathrm{c}}(\mathrm{x})\right)}{\sum_{\mathrm{c}^{\prime}}^{\mathrm{c}} \exp \left(\mathrm{L}_{\mathrm{c}^{\prime}}(\mathrm{x})\right)}
$$

where $\mathrm{c}$ is the number of building damage classes and $\operatorname{Lc}(\mathrm{x})$, the least-squares fit, is transformed in such a way that $\sum_{\mathrm{c}^{\prime}=1}^{\mathrm{c}} \mathrm{L}_{\mathrm{c}}(\mathrm{x})=0$.

\subsubsection{Logistic Regression (LR)}

The logistic regression (LR) model, developed by McFadden (1973) [56], is a multivariate regression analysis model that describes the relationship between a bivariate dependent parameter and several independent parameters [57] through the estimation of an optimal model. The addition of a link function suitable for a general linear regression model allows the parameter type to be continuous, discrete, or mixed, thus obviating the requirement for a normal distribution $[58,59]$. Some studies have shown that the LR model is more accurate than other types of models constructed for the same purpose [60-62]. The LR model based on a general linear model can be derived from Equations (8) and (9):

$$
\begin{gathered}
y=b_{0}+b_{1} x_{1}+b_{2} x_{2}+b_{3} x_{3}+\cdots+b_{n} x_{n} \\
P=\frac{e^{y}}{1+e^{y}}
\end{gathered}
$$

where $y$ is the linear logistic model, $b_{0}$ is the $y$-intercept, $b_{n}$ is the logistic coefficient of each factor, $\mathrm{n}$ is the number of factors controlling a seismic event, $\mathrm{x}$ is the earthquake conditioning factor, and $\mathrm{P}$ is the probability of damage (ranging from 0 to 1 ) in the event of an earthquake [60]. 


\section{Results}

\subsection{Building Damage Inventory Map}

The DPMs were generated from the Sentinel-1 dataset and geocoded to the Shuttle Radar Topography Mission (SRTM) digital elevation model (DEM), 1 arcsecond. Figure 6 reveals the map view of Sentinel-1 DPMs over Pohang. The assessment technique is most sensitive to the destruction of the built environment. Pixels are set to be relatively transparent where corresponding to areas where decorrelation did not significantly change during the time spanning the earthquake, suggesting little to no destruction. Increased opacity of the radar image pixels reflects increasing ground and building change or potential damage. The color range from yellow to red indicates an increasingly significant coherence change in the area covered by the pixel. Each pixel in the DPMs was registered to the SRTM DEM and had a corresponding dimension of about $30 \mathrm{~m}$.
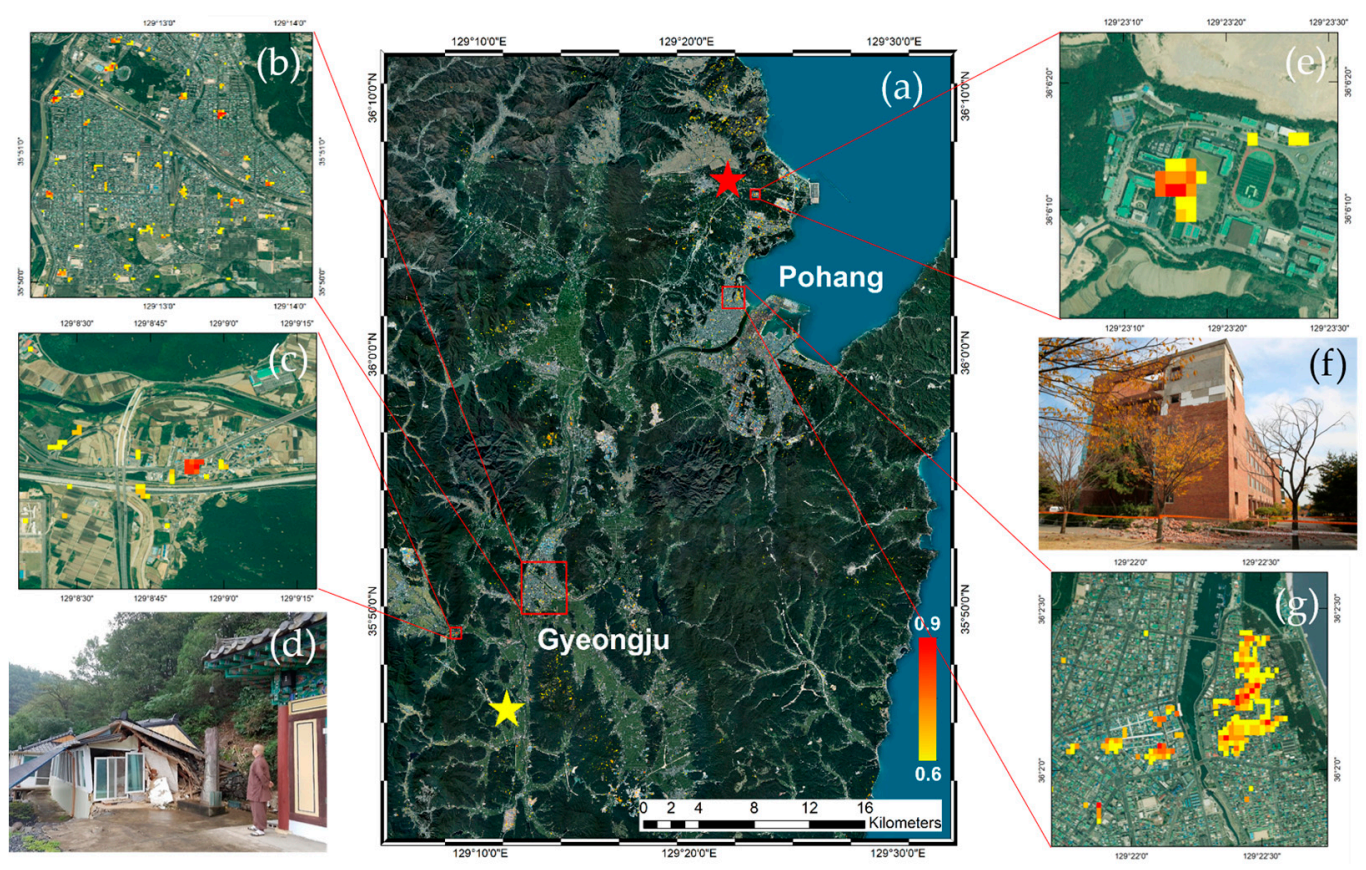

Figure 6. (a) Damage proxy maps (DPMs) after the Gyeongju and the Pohang earthquakes. DPM of (b) Seonggeon-dong and (c) Gwangmyeong-dong corresponding to (d) collapsed houses. DPM of (e) Handong Global University corresponding to (f) collapsed walls and in (g) Songdo-dong. Yellow to red pixels indicate increasingly more significant potential damage in seismic vulnerability mapping. Red and yellow stars indicate the epicenter of Pohang and Gyeongju earthquakes, respectively.

Here, we compared the distribution of coherence loss areas after the earthquakes throughout Gyeongju and Pohang, as seen in Figure 6a. According to the land cover map derived from the Korea Institute of Geoscience and Mineral Resources (KIGAM), Figure 6a reveals the DPM after the Gyeongju earthquake over residential, commercial, agricultural, and vegetated areas. Figure $6 \mathrm{~b}, \mathrm{c}$ show the widespread COD in Seonggeon-dong and Gwangmyeong-dong, respectively, corresponding to collapsed houses (Figure 6d [63]). These areas consist of residential and commercial areas. Figure 6a shows DPM that indicates COD over residential, commercial, industrial, agricultural, and vegetated areas affected by the Pohang earthquake. Some of the spatially large and strong coherence loss after the Pohang earthquake corresponds to Handong Global University (Figure 6e), associated with collapsed walls (Figure 6f), while Figure $6 \mathrm{~g}$ shows Songdo-dong district, consisting of residential areas. The DPM of the Pohang earthquake was then used as a building damage inventory map to produce a seismic vulnerability map using machine learning. 


\subsection{Relationship between Damaged Buildings and Related Factors}

FR values can provide information on the relationship between seismic vulnerability and related factors (geotechnical, physical, structural, social, and capacity). A ratio greater than 1 denotes that the class in the related factor has more impact on seismic vulnerability. The FR values calculated in this study are shown in Table 1. Building damage occurred in areas with elevations of $0-74 \mathrm{~m}$. The classes with a strong impact on seismic vulnerability were: slope of $0^{\circ}-2.44^{\circ}(\mathrm{FR}=3.50)$, elevation of $0-74 \mathrm{~m}(4.09)$, PGA of 3.37-28.56 gal (5.31), $0-26.90 \mathrm{~km}$ distance from epicenter (5.12), 7.36-39.08 km distance from fault (2.65), building constructed from concrete (2.63), building density of 1256-40,065 (5.13), building height of 7.88-422 m (2.31), commercial areas (3.99), child population of 228-10,747 (3.65), elderly population of 2252-31,218 (3.56), population density of 10,913-146,455 (5.17), 0-6.92 km distance from hospital (3.95), 0-3.39 km distance from police station (3.95), and 0-5.24 km distance from fire station (4.18). Areas in these classes are predicted to experience the highest degree of damage due to earthquakes.

Table 1. Frequency ratios of seismic-related factors.

\begin{tabular}{|c|c|c|c|c|}
\hline Factor & Class & Total $\%$ & Event $\%$ & Frequency Ratio \\
\hline \multirow{5}{*}{ Slope (degree) } & $0-2.44$ & 20.06 & 70.26 & 3.50 \\
\hline & $2.44-11.60$ & 20.21 & 24.47 & 1.21 \\
\hline & $11.60-18.32$ & 20.14 & 4.21 & 0.21 \\
\hline & $18.32-25.04$ & 19.79 & 0.92 & 0.05 \\
\hline & $25.04-77.89$ & 19.77 & 0.13 & 0.01 \\
\hline \multirow{5}{*}{ Elevation (m) } & $0-74$ & 20.02 & 81.79 & 4.09 \\
\hline & $74-153$ & 20.04 & 13.7 & 0.69 \\
\hline & $153-252$ & 19.99 & 4.48 & 0.23 \\
\hline & $252-407$ & 19.97 & 0 & 0 \\
\hline & $407-1898$ & 19.96 & 0 & 0 \\
\hline \multirow{5}{*}{ PGA (gal) } & $0-0.81$ & 17.97 & 0 & 0 \\
\hline & $0.81-1.48$ & 20.71 & 0 & 0 \\
\hline & $1.48-2.26$ & 23.86 & 0 & 0 \\
\hline & $2.26-3.37$ & 19.26 & 3.58 & 0.19 \\
\hline & $3.37-28.56$ & 18.17 & 96.41 & 5.31 \\
\hline \multirow{5}{*}{$\begin{array}{l}\text { Distance from } \\
\text { epicenter }(\mathrm{km})\end{array}$} & $0-26.90$ & 19.55 & 100 & 5.12 \\
\hline & $26.90-43.27$ & 19.96 & 0 & 0 \\
\hline & $43.27-58.48$ & 19.88 & 0 & 0 \\
\hline & $58.48-83.04$ & 20.61 & 0 & 0 \\
\hline & 83.04-149.12 & 19.97 & 0 & 0 \\
\hline \multirow{5}{*}{$\begin{array}{l}\text { Distance from fault } \\
\qquad(\mathrm{km})\end{array}$} & $0-0.92$ & 20.00 & 18.58 & 0.93 \\
\hline & $0.92-2.29$ & 20.00 & 8.33 & 0.42 \\
\hline & $2.29-4.14$ & 20.00 & 6.41 & 0.33 \\
\hline & $4.14-7.36$ & 19.99 & 13.71 & 0.69 \\
\hline & $7.36-39.08$ & 19.99 & 52.94 & 2.65 \\
\hline \multirow{6}{*}{$\begin{array}{l}\text { Construction } \\
\text { materials }\end{array}$} & Steel & 31.88 & 22.81 & 0.71 \\
\hline & Masonry & 28.81 & 20.70 & 0.71 \\
\hline & Concrete & 21.08 & 55.57 & 2.63 \\
\hline & Wood & 17.86 & 0.9 & 0.05 \\
\hline & Concrete and steel & 0.25 & 0 & 0 \\
\hline & Other & 0.10 & 0 & 0 \\
\hline \multirow{5}{*}{ Building density } & $0-157$ & 11.85 & 0 & 0 \\
\hline & $157-314$ & 29.08 & 0.51 & 0.02 \\
\hline & $314-628$ & 22.51 & 7.56 & 0.34 \\
\hline & $628-1256$ & 21.96 & 17.30 & 0.79 \\
\hline & $1256-40,065$ & 14.57 & 74.61 & 5.13 \\
\hline \multirow{5}{*}{$\begin{array}{l}\text { Building height } \\
(\mathrm{m})\end{array}$} & $0-1.57$ & 20.11 & 3.55 & 0.18 \\
\hline & $1.57-3.15$ & 20.76 & 7.32 & 0.36 \\
\hline & $3.15-4.73$ & 19.70 & 14.43 & 0.74 \\
\hline & $4.73-7.88$ & 19.72 & 29.28 & 1.49 \\
\hline & $7.88-402$ & 19.68 & 45.39 & 2.31 \\
\hline
\end{tabular}


Table 1. Cont.

\begin{tabular}{|c|c|c|c|c|}
\hline Factor & Class & Total $\%$ & Event \% & Frequency Ratio \\
\hline \multirow{12}{*}{ Land use } & Residential & 2.70 & 37.64 & 0.76 \\
\hline & Industrial & 0.81 & 13.64 & 0.92 \\
\hline & Commercial & 0.32 & 23.29 & 3.99 \\
\hline & $\begin{array}{c}\text { Culture, sports, } \\
\text { and recreation } \\
\text { facilities }\end{array}$ & 0.04 & 1.17 & 1.62 \\
\hline & $\begin{array}{c}\text { Transportation } \\
\text { area }\end{array}$ & 1.30 & 19.058 & 0.8 \\
\hline & Public facility area & 0.32 & 5.176 & 0.8 \\
\hline & Agricultural & 21.88 & 0 & 0 \\
\hline & Forest area & 66.71 & 0 & 0 \\
\hline & Grassland & 0.30 & 0 & 0 \\
\hline & Marsh & 0.73 & 0 & 0 \\
\hline & Bare ground & 1.72 & 0 & 0 \\
\hline & Water body & 2.06 & 0 & 0 \\
\hline \multirow{5}{*}{ Child population } & $0-22$ & 20.59 & 14.92 & 0.73 \\
\hline & $22-37$ & 20.85 & 2.57 & 0.13 \\
\hline & $37-60$ & 19.73 & 5.14 & 0.27 \\
\hline & $60-228$ & 19.68 & 7.59 & 0.39 \\
\hline & $228-10,747$ & 19.13 & 69.75 & 3.65 \\
\hline \multirow{5}{*}{ Elderly population } & $0-823$ & 20.00 & 18.01 & 0.91 \\
\hline & 823-1049 & 20.09 & 2.31 & 0.12 \\
\hline & 1049-1508 & 20.08 & 3.98 & 0.19 \\
\hline & $1508-2252$ & 20.13 & 5.79 & 0.29 \\
\hline & $2252-31,218$ & 19.68 & 69.88 & 3.56 \\
\hline \multirow{5}{*}{ Population density } & $0-1723$ & 19.04 & 13.32 & 0.69 \\
\hline & $1723-2872$ & 29.78 & 4.61 & 0.16 \\
\hline & $2872-4595$ & 22.50 & 2.90 & 0.13 \\
\hline & $4595-10,913$ & 14.91 & 8.17 & 0.55 \\
\hline & $10,913-146,455$ & 13.75 & 70.97 & 5.17 \\
\hline \multirow{5}{*}{$\begin{array}{l}\text { Distance from } \\
\text { hospital }(\mathrm{km})\end{array}$} & $0-6.92$ & 19.32 & 76.28 & 3.95 \\
\hline & $6.92-12.11$ & 20.99 & 18.58 & 0.89 \\
\hline & $12.11-17.59$ & 20.15 & 4.87 & 0.25 \\
\hline & $17.59-24.81$ & 19.90 & 0.25 & 0.02 \\
\hline & $24.81-73.56$ & 19.62 & 0 & 0 \\
\hline \multirow{5}{*}{$\begin{array}{c}\text { Distance from } \\
\text { police station }(\mathrm{km})\end{array}$} & $0-3.39$ & 17.89 & 70.51 & 3.95 \\
\hline & $3.39-5.66$ & 20.88 & 14.48 & 0.69 \\
\hline & $5.66-7.93$ & 20.16 & 8.71 & 0.44 \\
\hline & $7.93-11.32$ & 21.22 & 5.76 & 0.28 \\
\hline & $11.32-72.22$ & 19.83 & 0.51 & 0.03 \\
\hline \multirow{5}{*}{$\begin{array}{l}\text { Distance from fire } \\
\text { station }(\mathrm{km})\end{array}$} & $0-5.24$ & 18.94 & 79.35 & 4.18 \\
\hline & $5.24-8.84$ & 20.22 & 15.64 & 0.77 \\
\hline & $8.84-12.78$ & 20.50 & 3.84 & 0.18 \\
\hline & $12.78-18.35$ & 20.40 & 1.15 & 0.05 \\
\hline & $18.35-83.57$ & 19.91 & 0 & 0 \\
\hline
\end{tabular}

\subsection{Seismic Vulnerability Map}

Seismic vulnerability maps were made using the training dataset compiled using the building damage inventory map from the DPM of the Pohang earthquake and applying machine learning algorithms, as discussed above. A combination of 15 seismic-related factors served as the dependent variables, and can mainly be classified as geotechnical, physical, structural, social, and capacity indicators. LogitBoost (Figure 7a), LMT (Figure 7b), and LR (Figure $7 \mathrm{~b}$ ) machine learning algorithms were applied to produce the seismic vulnerability maps. Each pixel in the study area was assigned a specific building damage value using the natural breaks method [7]. The seismic vulnerability maps were classified as safe, low to moderate, high, and very high vulnerability classes. 


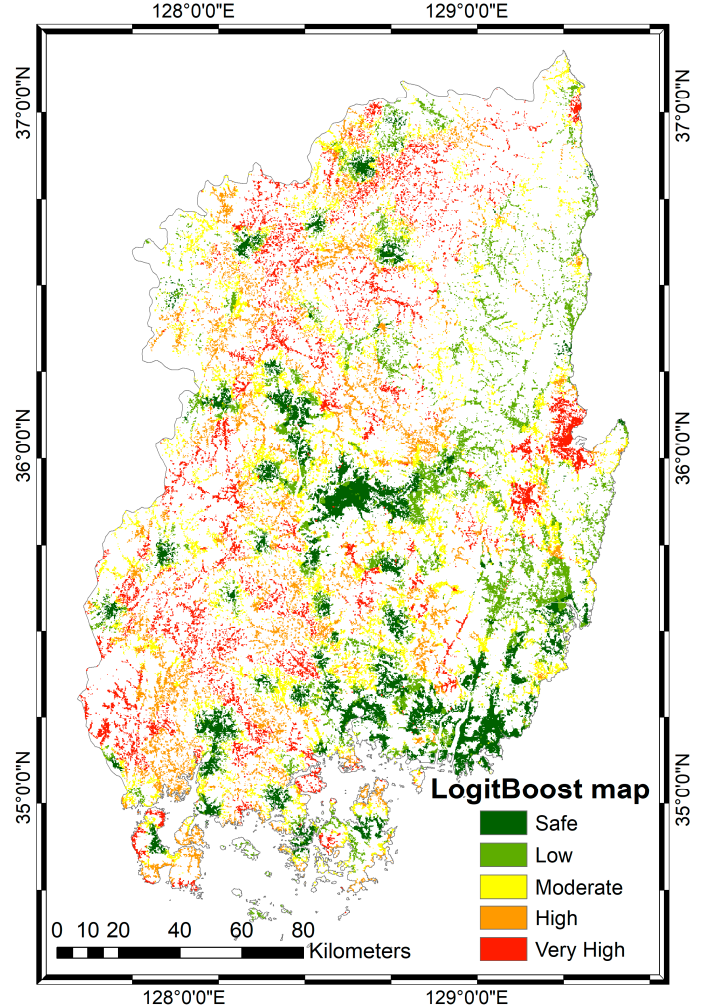

(a)

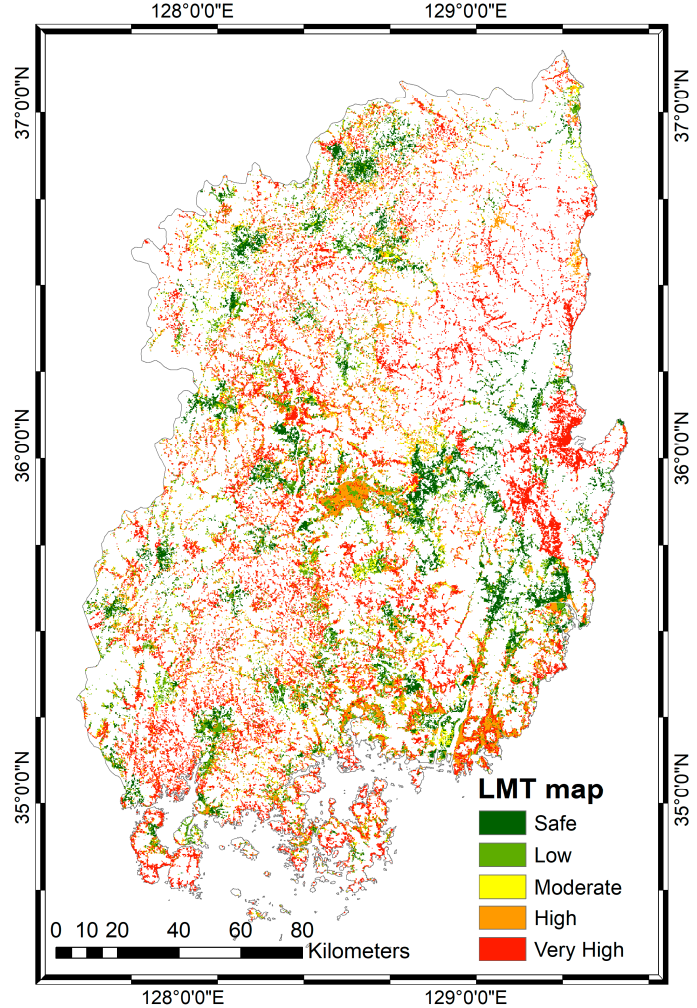

(b)

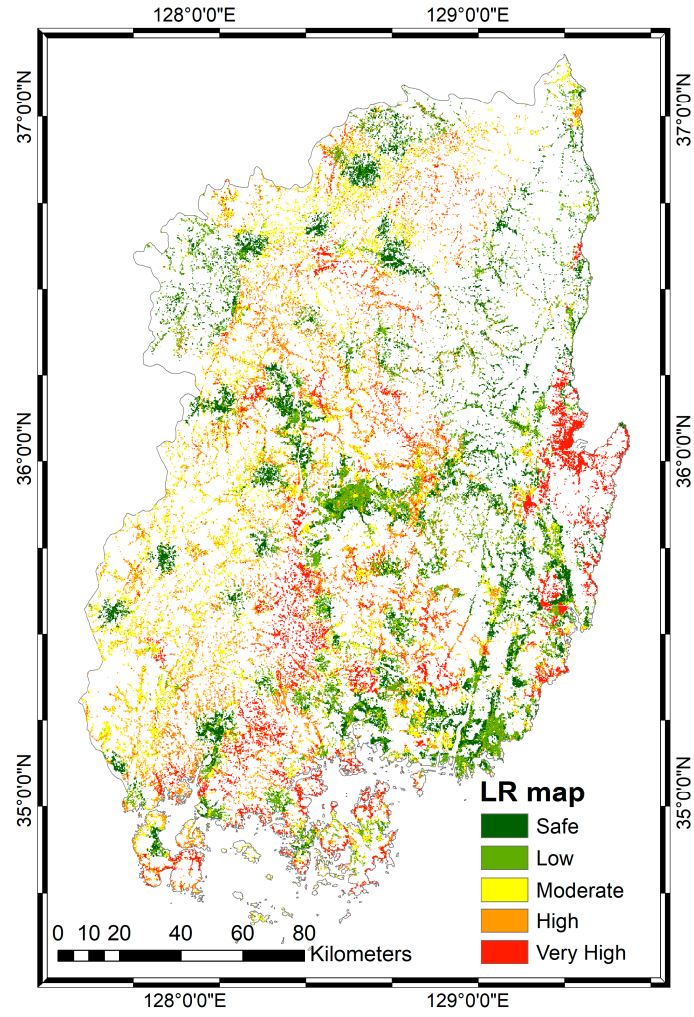

(c)

Figure 7. Seismic vulnerability map generated using three algorithms: (a) LogitBoost, (b) LMT, and (c) LR.

Figure 8 shows the distribution of pixels in each seismic vulnerability map generated by LogitBoost, LMT, and LR models. In the LogitBoost model, 29.53\% were classified as safe, $17.59 \%$ as low risk, $13.18 \%$ as moderate risk, $22.95 \%$ as high risk, and $16.74 \%$ as very 
high risk. Gyeongju and Pohang were found to be the most vulnerable to earthquake damage. Among big cities in the study area, Busan, Daegu, and Ulsan were classified as safe and low risk. For the LMT model, $19.74 \%$ were classified as safe, $18.54 \%$ as low risk, $8.25 \%$ as moderate risk, $18.27 \%$ as high risk, $35.20 \%$ as very high risk. Gyeongju and Pohang were found to be the most vulnerable to earthquake damage. Daegu was classified as a safe and low-risk city, while Busan and Ulsan were high and very high risk. In the LR model, $19.91 \%$ were classified as safe, $20.08 \%$ as low risk, $20.71 \%$ as moderate risk, $19.46 \%$ as high risk, and $19.85 \%$ as very high risk. The distribution of pixels in the low- and high-risk classes in Figure 8 shows similar results for each algorithm, although LMT shows larger numbers of pixels in very high-risk areas. The most vulnerable areas were Gyeongju and Pohang, whereas low and moderate risk areas were Busan and Ulsan. Seismic vulnerability classes were evenly distributed in Daegu.

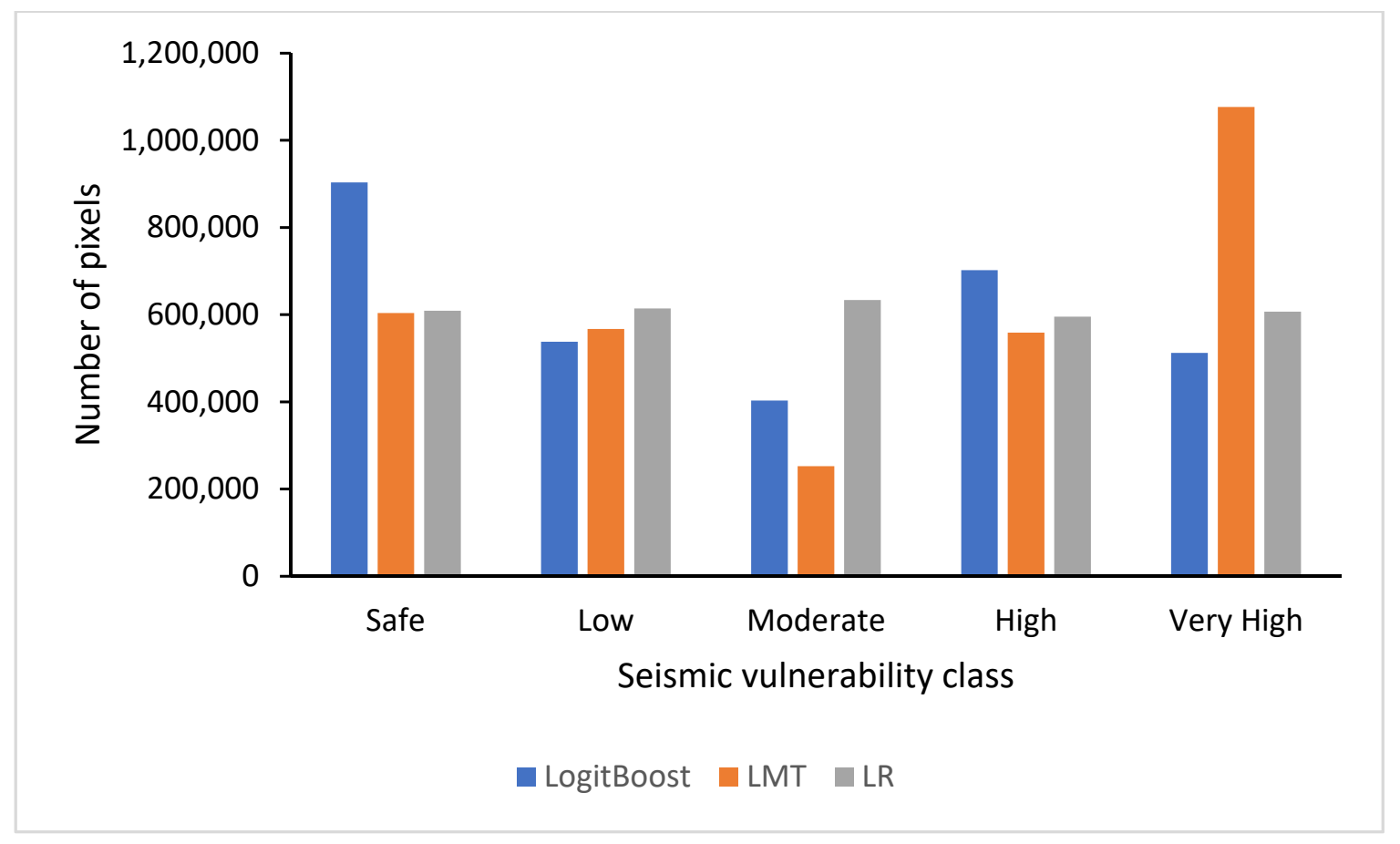

Figure 8. Distribution of pixels in seismic vulnerability classes for LogitBoost, LMT, and LR models.

\subsection{Model Validation}

A validation step was conducted to assess the reliability of the seismic vulnerability map from each algorithm. ROC curve analysis is a standard way of validating the probability models used to generate seismic vulnerability maps, according to the area under the curve (AUC) $[7,14,15]$. Higher values indicate more accurate and reliable models. If the AUC, which ranges from 0 to 1 , is lower than 0.5 , the model is considered unacceptably inaccurate [49]. The accuracy of the seismic vulnerability maps generated using the three algorithms was then evaluated based on ROC curve analysis of the testing dataset (50\% of all data). As seen in Figure 9, the AUC values were 0.769, 0.851, and 0.749 for LogitBoost, LMT, and logistic regression, respectively. Thus, the LMT model generated the best seismic vulnerability map in this study. The results indicate that the algorithms are useful to map seismic vulnerability in the southeastern Korean Peninsula. Since all of the AUC values were higher than 0.5 , the seismic vulnerability maps produced by all algorithms used in this study are acceptable for predicting vulnerable buildings in southeast Korea [49]. 
ROC Curve

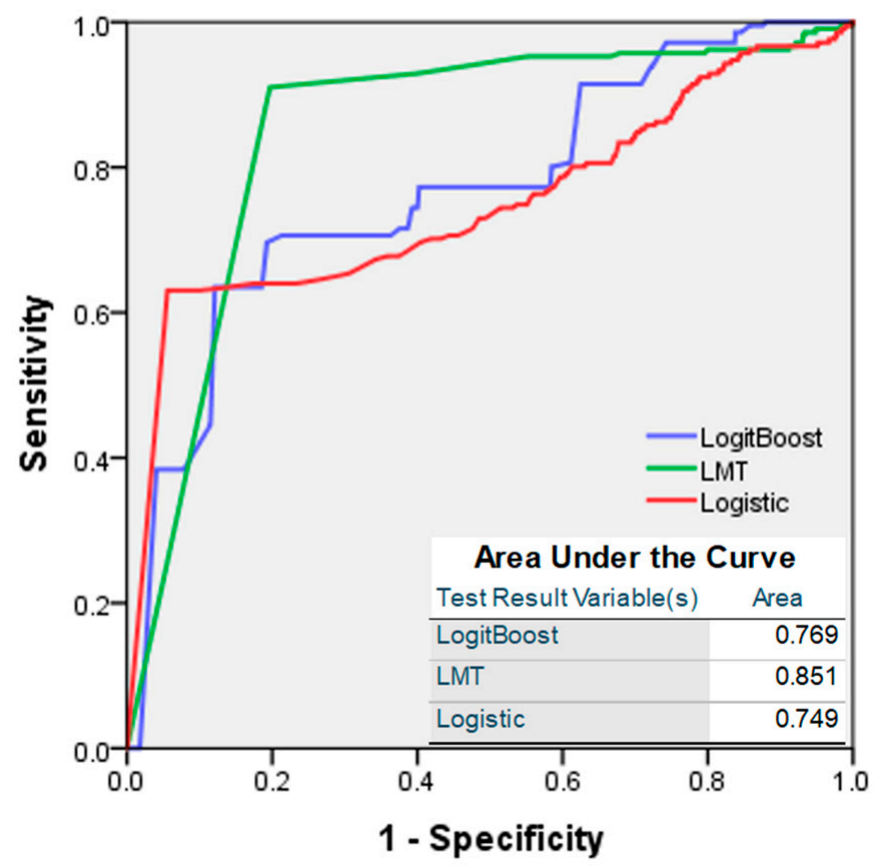

Figure 9. Receiver operating characteristic (ROC) curves associated with seismic vulnerability maps generated by LogitBoost, LMT, and LR algorithms.

\section{Discussion}

\subsection{Building Damage Inventory Map}

The building damage inventory map was generated through the DPM method after the Pohang earthquake using Sentinel-1 SAR data. We found a good correlation between the DPM result and the released map from the KMA report about the Pohang earthquake in our qualitative validation. Therefore, the building damage inventory map is reliable. The KMA map was derived from field survey and damage survey data from local governments. The map shows the distribution of the Pohang earthquake's magnitude using the modified Mercalli intensity (MMI) scale [34]. The results were similar to the KMA report that these areas suffered MMI VII to VIII. KMA defines MMI VII to VIII as damage to major structural parts such as pillars, walls, and roofs, even in well-designed and well-built buildings. KMA map also shows some areas that suffered MMI V to VI; however, the DPMs did not show any CODs in these areas. The scales showed that the damage was inside buildings, such as minor cracks in walls and damage caused by dropping objects or tiles; therefore, SAR cannot detect a significant coherence change.

Here, the total damaged areas from DPMs were calculated by multiplying the total number of pixels by the pixel cell size, which for the Gyeongju earthquake yielded an area of $1.09 \mathrm{~km}^{2}$ and the Pohang earthquake yielded an area of $1.32 \mathrm{~km}^{2}$. The KMA reported a total of 69 damaged buildings by the Gyeongju earthquake, and 504 damaged buildings by the Pohang earthquake (MMI VII and VIII). The Pohang earthquake caused more damage than the Gyeongju earthquake, some of which was due to the depth of the epicenter. The shallower the epicenter of an earthquake, the more damage it causes. The epicenter depth of the Pohang earthquake was $7 \mathrm{~km}$, while the epicenter depth of the Gyeongju earthquake was $15 \mathrm{~km}$. Additionally, the surface deformation in urban areas with high buildings caused by the Pohang earthquake affected the occurrence of damage in Pohang.

\subsection{Seismic Vulnerability Map}

Estimating the seismic vulnerability of an area is vital for environmental management and land use planning, among other applications [19]. Although many methods and techniques have been developed to assess earthquake hazards around the world to date, 
the goals of all these studies are to reduce the economic losses and resulting losses. The method used to create seismic vulnerability maps affects the quality of the mapping. Machine learning techniques are effective. In particular, the method used to generate training and testing data is important. Accurate damage building inventory maps can be obtained using the DPM method; we combined DPM and GIS spatial data to produce an accurate seismic vulnerability map.

The seismic vulnerability maps of all three algorithms used in this study revealed that Pohang and Gyeongju are the most vulnerable areas to earthquake damage. We analyzed seismic-related factors by comparing general patterns of damaged buildings with factor maps. Pohang and Gyeongju are the cities where the two largest recent earthquakes happened. Several factors in these areas had higher values, such as the value of PGA and the distance from the epicenter. Therefore, Gyeongju and Pohang were areas with a high risk of earthquake vulnerability. Buildings within $0-36.90 \mathrm{~km}$ of an epicenter corresponded to damaged buildings. This result confirms that most buildings close to epicenters were damaged. The results revealed that areas with a high risk had high population and building density, including Gyeongju and Pohang. Similar to Gyeongju and Pohang, Busan, Daegu, and Ulsan are cities with a high density of buildings and populations. These cities consist of areas of low to moderate risk of seismic vulnerability. One of the main causes of a high risk of seismic damage in countryside areas is wood as a building construction material, while buildings constructed with steel reinforced with concrete have a lower level of seismic vulnerability. Therefore, attention should be paid to reconstruction, retrofitting, or renovation of the buildings in these areas.

Seismic vulnerability maps were validated based on ROC curves and AUC values to assess the accuracy of the maps using testing data, which comprised $50 \%$ of the total dataset. The AUC data showed that the LMT algorithm had the highest accuracy of $85.10 \%$, which was $8.2 \%$ higher than the LogitBoost algorithm and $10.2 \%$ higher than the logistic regression algorithm. Therefore, the LMT algorithm is better to produce seismic vulnerability maps than LogitBoost and logistic regression algorithms.

A survey was conducted with 1256 Korean citizens using a questionnaire of citizen earthquake literacy (CEL) during spring 2020. The survey was based on three dimensions, including citizen knowledge, awareness, and management. We developed 15 questions associated with three dimensions. Table A1 in Appendix A presents the questionnaire that consists of five questions for each dimension, and all questions are configured to be answered on a 5-point Likert scale (strongly agree, agree, neutral, disagree, and strongly disagree). Principal component analysis as an exploratory factor analysis approach was used to examine if the items corresponded to each other and explore the construct validity of the instrument. Cronbach's alpha when an item was deleted was also calculated to see whether the items in the construct reliably measured the same latent variable. Cronbach's alpha values for each dimension were $0.847,0.822$, and 0.849 , respectively. Furthermore, Cronbach's alpha when an item was deleted in this study was found to be between 0.77 and 0.84 . This result indicated that the survey data used in this study were strongly reliable and consistent [64].

To characterize the profile of participants with higher (or lower) levels of seismic literacy, difference in means analyses using a $t$-test, ANOVA test, and Tukey's honestly significant difference (HSD) post hoc test were carried out. Table 2 shows the average values associated with earthquake literacy, including seismic knowledge, awareness, and management, broken down by sociodemographic characteristics of the participants. The $t$-test result shows that male citizens have higher earthquake literacy but not significantly more than female citizens in all three aspects. The ANOVA test was conducted to determine whether there were differences in the subcategories of seismic literacy depending on age, risk awareness, and final educational background. The results show that participants 20 years of age and below, and 60 years of age and above, declared a higher level of seismic literacy than participants between 30 and 50 years of age. Participants in their 30 s declared the lowest level of seismic awareness and participants in their 40s declared the lowest level 
of seismic knowledge and management among the different age groups. However, there was no significant difference in earthquake literacy in all aspects among all ranges of ages (under 20s to over 60s). Only participants who were aware that where they live is absolutely safe from earthquakes had a statistically significantly higher level of seismic management behavior. They also declared a higher level of seismic knowledge. Participants who were aware that where they live is not safe at all from earthquakes declared a higher level of seismic awareness but declared the lowest level of seismic knowledge and management. This result is an important warning sign for local and regulatory authorities to raise the citizen seismic knowledge and management. In the latter case, participants in graduate school and graduate school graduates declared a higher level of seismic literacy in all three aspects. Participants with an education level of less than high school declared the lowest level of seismic knowledge and high school graduates declared the lowest level of seismic awareness and management.

Table 2. Mean values for seismic literacy.

\begin{tabular}{|c|c|c|c|c|c|c|c|c|}
\hline & & \multirow{2}{*}{$\%$} & \multicolumn{2}{|c|}{ Knowledge } & \multicolumn{2}{|c|}{ Awareness } & \multicolumn{2}{|c|}{ Management } \\
\hline \multicolumn{2}{|c|}{ All Samples $(n=1256)$} & & Mean & SD & Mean & SD & Mean & SD \\
\hline \multirow[t]{2}{*}{ Gender } & Male & 50.96 & 3.1988 & 0.6655 & 3.1428 & 0.6937 & 3.1759 & 0.6299 \\
\hline & Female & 49.04 & 2.9032 & 0.7008 & 2.9659 & 0.6591 & 2.8484 & 0.6515 \\
\hline \multirow[t]{5}{*}{ Age Group } & Under 20 & 17.75 & 3.1274 & 0.7671 & 3.1229 & 0.6648 & 3.1157 & 0.6535 \\
\hline & $30 \mathrm{~s}$ & 19.11 & 3.0008 & 0.7141 & 2.9442 & 0.7138 & 2.9450 & 0.7019 \\
\hline & $40 \mathrm{~s}$ & 22.37 & 2.9993 & 0.6652 & 2.9929 & 0.6592 & 2.9117 & 0.6303 \\
\hline & $50 \mathrm{~s}$ & 23.49 & 3.0414 & 0.6664 & 3.0569 & 0.6684 & 3.0285 & 0.6372 \\
\hline & Over 60 & 17.28 & 3.1244 & 0.6862 & 3.1917 & 0.6886 & 3.1060 & 0.6692 \\
\hline \multirow[t]{5}{*}{$\begin{array}{c}\text { Risk } \\
\text { Awareness }\end{array}$} & $\begin{array}{c}\text { No, not at } \\
\text { all }\end{array}$ & 6.13 & 2.9974 & 0.7877 & 3.1922 & 0.7756 & 2.9299 & 0.7812 \\
\hline & $\begin{array}{c}\text { No, hardly } \\
\text { not }\end{array}$ & 29.30 & 3.0538 & 0.7050 & 3.0946 & 0.7120 & 2.9533 & 0.6851 \\
\hline & $\begin{array}{l}\text { It's normal } \\
\text { Yes, to }\end{array}$ & 41.64 & 3.0164 & 0.6718 & 3.0191 & 0.6340 & 2.9897 & 0.6121 \\
\hline & $\begin{array}{l}\text { some } \\
\text { extent }\end{array}$ & 20.46 & 3.1354 & 0.6694 & 3.0412 & 0.6471 & 3.1447 & 0.6095 \\
\hline & $\begin{array}{c}\text { Yes, } \\
\text { absolutely }\end{array}$ & 2.47 & 3.1484 & 0.9946 & 3.0065 & 1.0462 & 3.3226 & 0.9888 \\
\hline \multirow[t]{6}{*}{$\begin{array}{c}\text { Final } \\
\text { Education }\end{array}$} & $\begin{array}{l}\text { Under high } \\
\text { school }\end{array}$ & 1.11 & 2.7857 & 0.8282 & 3.1000 & 0.8727 & 3.0571 & 0.8821 \\
\hline & $\begin{array}{c}\text { High } \\
\text { school } \\
\text { graduate }\end{array}$ & 16.16 & 2.8512 & 0.6770 & 2.9586 & 0.6560 & 2.8975 & 0.6496 \\
\hline & $\begin{array}{l}\text { In college } \\
\text { (or } \\
\text { university) }\end{array}$ & 5.81 & 3.3151 & 0.6960 & 3.3014 & 0.6482 & 3.2877 & 0.5588 \\
\hline & $\begin{array}{c}\text { College (or } \\
\text { university) } \\
\text { graduate }\end{array}$ & 5.81 & 3.0227 & 0.6805 & 3.0336 & 0.6759 & 2.9755 & 0.6516 \\
\hline & $\begin{array}{l}\text { In graduate } \\
\text { school }\end{array}$ & 64.41 & 3.4762 & 0.6999 & 3.1048 & 0.6888 & 3.3524 & 0.5759 \\
\hline & $\begin{array}{c}\text { Graduate } \\
\text { school } \\
\text { graduate }\end{array}$ & 10.83 & 3.3632 & 0.6685 & 3.1912 & 0.7176 & 3.2250 & 0.6818 \\
\hline
\end{tabular}

Further analysis was conducted to find significant differences through Tukey's HSD post hoc test and showed that citizens who were aware that where they live is absolutely safe from earthquakes had a statistically significantly higher level of seismic management behavior. Participants with a highly educated background had the highest level of seismic knowledge. 
The participants of 60 years old and above declared the highest level of seismic literacy. Some authors posit that this could be explained because adults in this stage of life have acquired greater experience and care responsibilities (either for others or their assets), which may give rise to increased interest in involving themselves in preparedness measures [65]. Participants' educational background also influenced their seismic literacy, especially in seismic knowledge, in line with previous studies $[66,67]$. Groups with less seismic literacy should be a target of intervention in order to raise earthquake risk awareness and motivate them to adopt preparedness actions.

Nevertheless, in general, the participants declared relatively low earthquake literacy, including seismic knowledge, awareness, and preparedness. This means that they are not properly prepared for earthquake hazards. For the areas that were classified as highly vulnerable to earthquakes, the focus should be on building reconstruction and retrofitting [16], whereas for those in moderate-risk areas, the focus should be on building renovation to reduce their seismic vulnerability. Areas with high building and population densities, such as Daegu, Busan, and Ulsan, should develop education programs to improve earthquake risk awareness and seismic literacy. The government could increase earthquake literacy, starting with a conscious approach to Korean citizens, especially in high vulnerability areas.

Finally, the institution responsible for developing local disaster risk reduction plans and programs should appropriately characterize their target audiences and areas if they expect to obtain more effective and efficient results. We expect that the results reported in this study will be useful input to achieve this. However, this study has certain limitations. First, the questionnaire could provide more information of the participants profile such as marital status, children in the house, annual household income, and household type and could be analyzed to provide specific information about participants' preparedness. Future studies could investigate the interaction between these variables to find specific patterns of seismic literacy.

\section{Conclusions}

We conducted a survey of 1256 participants to investigate the seismic literacy of Korean citizens, including seismic knowledge, awareness, and management, using a questionnaire of citizen earthquake literacy (CEL) following the 2017 Pohang earthquake. The results declared that the citizens had low literacy, which means that they are not properly prepared for earthquake hazards. To develop an earthquake risk reduction plan and program efficiently and effectively, not only must one appropriately characterize the target audience, but also indicate high potential earthquake zones and potential earthquake damage. Therefore, this study mapped and analyzed the seismic vulnerability in southeast Korea using LogitBoost, logistic model tree (LMT), and logistic regression (LR) machine learning algorithms based on a building damage inventory map. The building damage locations were generated after the 2017 Pohang earthquake using the damage proxy map (DPM) method from the Sentinel-1 synthetic aperture radar (SAR) data. The DPMs manage to detect coherence loss, which indicates damaged buildings in residential and commercial areas due to the Pohang earthquake and show a good correlation with the Korea Meteorological Administration (KMA) report with modified Mercalli intensity (MMI) scale values of more than VII (seven). The damage locations were randomly divided into two datasets: $50 \%$ for training the vulnerability models and $50 \%$ for validating the models in terms of accuracy and reliability. Fifteen seismic-related factors were used to construct a model for each algorithm. Model validation based on the area under the receiver operating curve (AUC) was used to determine model accuracy. The AUC values of seismic vulnerability maps using the LogitBoost, LMT, and LR algorithms were $0.769,0.851$, and 0.749 , respectively. We suggest that earthquake preparedness efforts should focus on reconstruction, retrofitting, renovation, and seismic education in areas with high seismic vulnerability in South Korea. The results of this study are expected to be beneficial for engineers and 
policymakers aiming at developing disaster risk reduction plans, policies, and programs due to future seismic activity in South Korea.

Author Contributions: Conceptualization, C.-W.L. and K.-Y.L.; methodology, M.S. and M.H.; software, M.S. and M.H.; validation. K.-Y.L., M.S. and J.H.; formal analysis, C.-W.L.; investigation, J.H. and M.H.; resources, M.S.; data curation, M.S., M.H. and J.H.; writing-original draft preparation, A.S.N.; writing—review and editing, M.S., A.S.N. and J.H.; visualization, M.S.; supervision, K.-Y.L.; project administration, J.H.; funding acquisition, K.-Y.L. All authors have read and agreed to the published version of the manuscript.

Funding: This research was supported by a grant from the National Research Foundation of Korea provided by the government of Korea (No. 2019R1A2C1085686) and also supported by a 2020 Research Grant from Kangwon National University.

Institutional Review Board Statement: Not applicable.

Informed Consent Statement: Informed consent was obtained from all subjects involved in the study.

Data Availability Statement: The dataset of seismic-related factor can be found on: https: / www. bigdata-environment.kr/user/main.do (accessed on 31 March 2021). Sentinel-1 A/B SAR images are freely available by European Space Agency and distributed and archived by Alaska Satellite Facility (https:/ / search.asf.alaska.edu/\#/ (accessed on 31 March 2021)). The DEM SRTM data and epicenter location used in this study were obtained from the United States Geological Survey (USGS) (https: / / earthexplorer.usgs.gov / (accessed on 31 March 2021) and https:/ / earthquake.usgs.gov/ earthquakes/map (accessed on 31 March 2021)).

Conflicts of Interest: The authors declare no conflict of interest.

\section{Appendix A}

Table A1. Survey questions asked by a researcher to prompt discussion.

\begin{tabular}{|c|c|c|c|c|c|c|}
\hline No & Knowledge & 1 & 2 & 3 & 4 & 5 \\
\hline 1. & I know why earthquakes occur & 1.91 & 11.94 & 42.68 & 38.14 & 5.33 \\
\hline 2. & I can distinguish between earthquake magnitude and scale & 4.70 & 25.16 & 37.02 & 29.22 & 3.90 \\
\hline 3. & $\begin{array}{l}\text { I can explain the terms related to earthquakes (e.g., epicenter, hypocenter, } \\
\text { main earthquake, aftershock) }\end{array}$ & 5.89 & 25.51 & 38.06 & 25.08 & 4.46 \\
\hline 4. & I do not have problem understanding earthquake news or articles & 0.64 & 10.27 & 39.01 & 42.36 & 7.72 \\
\hline 5. & I know how and what technology is used to study earthquakes & 11.39 & 41.24 & 36.15 & 9.00 & 2.23 \\
\hline \multicolumn{7}{|c|}{ Awareness } \\
\hline 6. & I know the shelter close to my home for escaping from earthquakes & 5.49 & 29.94 & 35.67 & 25.32 & 3.58 \\
\hline 7. & I know prevention items when earthquakes occur & 8.44 & 42.68 & 32.96 & 14.01 & 1.91 \\
\hline 8. & I know the earthquake will affect to my area and social community & 2.15 & 14.09 & 33.52 & 42.12 & 8.12 \\
\hline 9. & I know what to do when earthquakes happen & 0.88 & 11.86 & 38.14 & 43.15 & 5.97 \\
\hline 10. & I know the earthquake early warning service & 4.38 & 26.27 & 40.21 & 26.51 & 2.63 \\
\hline \multicolumn{7}{|c|}{ Management } \\
\hline 11. & I have a calm attitude for earthquakes & 2.55 & 21.66 & 49.28 & 23.73 & 2.79 \\
\hline 12. & I can handle terror, fear in earthquake situations & 3.66 & 26.04 & 46.10 & 21.74 & 2.47 \\
\hline 13. & $\begin{array}{l}\text { I changed my house to reduce damage, e.g., falling furniture or broken } \\
\text { glass, when earthquakes happen }\end{array}$ & 8.04 & 37.98 & 35.67 & 16.48 & 1.83 \\
\hline 14. & I can rapidly follow the earthquake early warning (message) service & 2.23 & 13.93 & 45.70 & 34.08 & 4.06 \\
\hline 15. & I can return to daily life after an earthquake & 1.83 & 13.38 & 49.12 & 32.40 & 3.26 \\
\hline
\end{tabular}

1. Yes, absolutely; 2. Yes; 3. It's normal; 4 . No; 5 . Absolutely not. 


\section{References}

1. Kim, Y.S.; Park, J.Y.; Kim, J.H.; Shin, H.C.; Sanderson, D.J. Thrust geometries in unconsolidated Quaternary sediments and evolution of the Eupchon Fault, southeast Korea. Isl. Arc 2004, 13, 403-415. [CrossRef]

2. Lee, K.; Yang, W.S. Historical seismicity of Korea. Bull. Seismol. Soc. Am. 2006, 96, 846-855. [CrossRef]

3. Kang, S.; Kim, B.; Bae, S.; Lee, H.; Kim, M. Earthquake-Induced Ground Deformations in the Low-Seismicity Region: A Case of the 2017 M5.4 Pohang, South Korea, Earthquake. Earthq. Spectra 2019, 35, 1235-1260. [CrossRef]

4. Grigoli, F.; Cesca, S.; Rinaldi, A.P.; Manconi, A.; López-Comino, J.A.; Clinton, J.F.; Westaway, R.; Cauzzi, C.; Dahm, T.; Wiemer, S. The November $2017 \mathrm{M}_{\mathrm{w}} 5.5$ Pohang earthquake: A possible case of induced seismicity in South Korea. Science 2018, 360, 1003-1006. [CrossRef] [PubMed]

5. Woo, J.-U.; Kim, M.; Sheen, D.-H.; Kang, T.-S.; Rhie, J.; Grigoli, F.; Ellsworth, W.L.; Giardini, D. An In-Depth Seismological Analysis Revealing a Causal Link between the $2017 \mathrm{M}_{\mathrm{W}} 5.5$ Pohang Earthquake and EGS Project. J. Geophys. Res. Solid Earth 2019, 124, 13060-13078. [CrossRef]

6. Lee, K.-K. Summary Report of the Korean Government Commision on Relation between the 2017 Pohang Earthquake and EGS Project; The Geological Society of Korea: Seoul, Korea, 2019.

7. Han, J.; Kim, J.; Park, S.; Son, S.; Ryu, M. Seismic Vulnerability Assessment and Mapping of Gyeongju, South Korea Using Frequency Ratio, Decision Tree, and Random Forest. Sustainability 2020, 12, 7787. [CrossRef]

8. Sang-Sun toward Better Risk Preparedness for Cultural Heritage. Available online: http://www.koreanheritage.kr//inside/ view.jsp?articleNo=15 (accessed on 19 January 2021).

9. Doo, R. Artifacts Damaged in Record-Breaking Earthquake in Gyeongju. Available online: https://www.thejakartapost.com/ life/2016/09/19/artifacts-damaged-in-record-breaking-earthquake-in-gyeongju.html (accessed on 18 January 2021).

10. Werner, C.; Wegmüller, U.; Strozzi, T.; Wiesmann, A. GAMMA SAR and interferometric processing software. In Proceedings of the ERS-ENVISAT Symposium, Gothenburg, Sweden, 16-20 October 2000; Special Publication ESA SP. European Space Agency: Paris, France, 2000; pp. 211-219.

11. Zebker, H.A.; Goldstein, R.M. Topographic Mapping from Interferometric Synthetic Aperture Radar Observations. In DigestInternational Geoscience and Remote Sensing Symposium (IGARSS); IEEE: New York, NY, USA, 1985; pp. $113-117$.

12. Panahi, M.; Rezaie, F.; Meshkani, S.A. Seismic vulnerability assessment of school buildings in Tehran city based on AHP and GIS. Nat. Hazards Earth Syst. Sci. Discuss. 2013, 1, 4511-4538. [CrossRef]

13. Jena, R.; Pradhan, B.; Beydoun, G. Earthquake vulnerability assessment in Northern Sumatra province by using a multi-criteria decision-making model. Int. J. Disaster Risk Reduct. 2020, 46, 101518. [CrossRef]

14. Yariyan, P.; Avand, M.; Soltani, F.; Ghorbanzadeh, O.; Blaschke, T. Earthquake vulnerability mapping using different hybrid models. Symmetry 2020, 12, 405. [CrossRef]

15. Han, J.; Park, S.; Kim, S.; Son, S.; Lee, S.; Kim, J. Performance of Logistic Regression and Support Vector Machines for Seismic Vulnerability Assessment and Mapping: A Case Study of the 12 September 2016 ML5.8 Gyeongju Earthquake, South Korea. Sustainability 2019, 11, 7038. [CrossRef]

16. Alizadeh, M.; Hashim, M.; Alizadeh, E.; Shahabi, H.; Karami, M.; Beiranvand Pour, A.; Pradhan, B.; Zabihi, H. Multi-Criteria Decision Making (MCDM) Model for Seismic Vulnerability Assessment (SVA) of Urban Residential Buildings. ISPRS Int. J. Geo-Inf. 2018, 7, 444. [CrossRef]

17. Han, J.; Kim, J. GIS-Based Seismic Vulnerability Mapping and Assessment Using AHP: A Case Study of Gyeongju, Korea. Korean J. Remote Sens. 2019, 35, 217-228.

18. Rezaie, F.; Panahi, M. GIS modeling of seismic vulnerability of residential fabrics considering geotechnical, structural, social and physical distance indicators in Tehran using multi-criteria decision-making techniques. Nat. Hazards Earth Syst. Sci. 2015, 15, 461-474. [CrossRef]

19. Lee, S.; Panahi, M.; Pourghasemi, H.R.; Shahabi, H.; Alizadeh, M.; Shirzadi, A.; Khosravi, K.; Melesse, A.M.; Yekrangnia, M.; Rezaie, F.; et al. SEVUCAS: A Novel GIS-Based Machine Learning Software for Seismic Vulnerability Assessment. Appl. Sci. 2019, 9, 3495. [CrossRef]

20. Yun, S.-H.; Hudnut, K.; Owen, S.; Webb, F.; Simons, M.; Sacco, P.; Gurrola, E.; Manipon, G.; Liang, C.; Fielding, E.; et al. Rapid Damage Mapping for the $2015 \mathrm{M}_{\mathrm{w}}$ 7.8 Gorkha Earthquake Using Synthetic Aperture Radar Data from COSMO-SkyMed and ALOS-2 Satellites. Seismol. Res. Lett. 2015, 86, 1549-1556. [CrossRef]

21. Tay, C.W.J.; Yun, S.-H.; Chin, S.T.; Bhardwaj, A.; Jung, J.; Hill, E.M. Rapid flood and damage mapping using synthetic aperture radar in response to Typhoon Hagibis, Japan. Sci. Data 2020, 7, 100-108. [CrossRef] [PubMed]

22. Hough, S.E.; Yun, S.-H.; Jung, J.; Thompson, E.; Parker, G.A.; Stephenson, O. Near-Field Ground Motions and Shaking from the 2019 Mw 7.1 Ridgecrest, California, Mainshock: Insights from Instrumental, Macroseismic Intensity, and Remote-Sensing Data. Bull. Seismol. Soc. Am. 2020, 110, 1506-1516. [CrossRef]

23. Biass, S.; Jenkins, S.; Lallemant, D.; Lim, T.N.; Williams, G.; Yun, S.-H. Remote sensing of volcanic impacts. In Forecasting and Planning for Volcanic Hazards, Risks, and Disasters; Elsevier: Amsterdam, The Netherlands, 2021; pp. 473-491.

24. Choe, B.-N. The National Atlas of Korea; National Geography Information Institute: Suwon, Korea, 2019.

25. Korean Statistical Information Service Statistics Korea. Population Census. Available online: https:// kosis.kr/statHtml/statHtml. do?orgId=101\&tblId=DT_1IN1502\&conn_path=I2\&language=en (accessed on 21 January 2020). 
26. Kim, H.-S.; Sun, C.-G.; Cho, H.-I. Geospatial Assessment of the Post-Earthquake Hazard of the 2017 Pohang Earthquake Considering Seismic Site Effects. ISPRS Int. J. Geo-Inf. 2018, 7, 375. [CrossRef]

27. Kim, Y.; Rhie, J.; Kang, T.-S.; Kim, K.-H.; Kim, M.; Lee, S.-J. The 12 September 2016 Gyeongju earthquakes: 1. Observation and remaining questions. Geosci. J. 2016, 20, 747-752. [CrossRef]

28. Jin, K.; Lee, J.; Lee, K.-S.; Kyung, J.B.; Kim, Y.-S. Earthquake damage and related factors associated with the $2016 \mathrm{ML}=5.8$ Gyeongju earthquake, southeast Korea. Geosci. J. 2020, 24, 141-157. [CrossRef]

29. Korea Meteorological Administration. 2018 Earthquake Annual Report; Korea Meteorological Administration: Seoul, Korea, 2019.

30. Korea Meteorological Administration. 2019 Earthquake Annual Report; Korea Meteorological Administration: Seoul, Korea, 2020.

31. MML, S.; Mote, T.; Pappin, J. Seismic hazard assessment of South Korea. In Proceedings of the Japanese Geotechnical Society Special Publication; Japanese Geotechnical Society: Tokyo, Japan, 2000; pp. 755-760.

32. Ellsworth, W.L.; Giardini, D.; Townend, J.; Ge, S.; Shimamoto, T. Triggering of the Pohang, Korea, Earthquake (Mw 5.5) by enhanced geothermal system stimulation. Seismol. Res. Lett. 2019, 90, 1844-1858. [CrossRef]

33. Zebker, H.A.; Villasenor, J. Decorrelation in interferometric radar echoes. IEEE Trans. Geosci. Remote Sens. 1992, 30, 950-959. [CrossRef]

34. Korea Meteorological Administration. Pohang Eartquake Analysis Report; Korea Meteorological Administration: Seoul, Korea, 2018.

35. Yariyan, P.; Karami, M.R.; Ali Abbaspour, R. Exploitation of Mcda to Learn the Radial Base Neural Network (rbfnn) Aim Physical and Social Vulnerability Analysis Versus the Earthquake (Case Study: Sanandaj City, Iran). ISPRS Int. Arch. Photogramm. Remote Sens. Spat. Inf. Sci. 2019, XLII-4/W18, 1071-1078. [CrossRef]

36. Pachauri, A.K.; Pant, M. Landslide hazard mapping based on geological attributes. Eng. Geol. 1992, 32, 81-100. [CrossRef]

37. Kim, K.-H.; Kang, T.-S.; Rhie, J.; Kim, Y.; Park, Y.; Kang, S.Y.; Han, M.; Kim, J.; Park, J.; Kim, M.; et al. The 12 September 2016 Gyeongju earthquakes: 2. Temporary seismic network for monitoring aftershocks. Geosci. J. 2016, 20, 753-757. [CrossRef]

38. Kang, T.-S.; Kim, D.K. Convergence Research Review; Convergence Research Policy Center: Seoul, Korea, 2017.

39. Sivakumar, N.; Karthik, S.; Thangaraj, S.; Saravanan, S.; Shidhardhan, C.K. Seismic Vulnerability of Open Ground Floor Columns in Multi Storey Buildings. Int. J. Sci. Eng. Res. 2013, 1, 52-58.

40. Cole, G.L.; Dhakal, R.P.; Turner, F.M. Building pounding damage observed in the 2011 Christchurch earthquake. Earthq. Eng. Struct. Dyn. 2012, 41, 893-913. [CrossRef]

41. Rimal, B.; Baral, H.; Stork, N.; Paudyal, K.; Rijal, S. Growing City and Rapid Land Use Transition: Assessing Multiple Hazards and Risks in the Pokhara Valley, Nepal. Land 2015, 4, 957-978. [CrossRef]

42. Hassanzadeh, R.; Nedović-Budić, Z.; Alavi Razavi, A.; Norouzzadeh, M.; Hodhodkian, H. Interactive approach for GIS-based earthquake scenario development and resource estimation (Karmania hazard model). Comput. Geosci. 2013, 51, 324-338. [CrossRef]

43. Rahman, N.; Ansary, M.A.; Islam, I. GIS based mapping of vulnerability to earthquake and fire hazard in Dhaka city, Bangladesh. Int. J. Disaster Risk Reduct. 2015, 13, 291-300. [CrossRef]

44. Armaş, I.; Toma-Danila, D.; Ionescu, R.; Gavriş, A. Vulnerability to Earthquake Hazard: Bucharest Case Study, Romania. Int. J. Disaster Risk Sci. 2017, 8, 182-195. [CrossRef]

45. Karimzadeh, S.; Miyajima, M.; Hassanzadeh, R.; Amiraslanzadeh, R.; Kamel, B. A GIS-based seismic hazard, building vulnerability and human loss assessment for the earthquake scenario in Tabriz. Soil Dyn. Earthq. Eng. 2014, 66, 263-280. [CrossRef]

46. Pradhan, B.; Abokharima, M.H.; Jebur, M.N.; Tehrany, M.S. Land subsidence susceptibility mapping at Kinta Valley (Malaysia) using the evidential belief function model in GIS. Nat. Hazards 2014, 73, 1019-1042. [CrossRef]

47. Hakim, W.; Achmad, A.; Lee, C.-W. Land Subsidence Susceptibility Mapping in Jakarta Using Functional and Meta-Ensemble Machine Learning Algorithm Based on Time-Series InSAR Data. Remote Sens. 2020, 12, 3627. [CrossRef]

48. Moung-Jin, L.; Won-Kyong, S.; Joong-Sun, W.; Inhye, P.; Saro, L. Spatial and temporal change in landslide hazard by future climate change scenarios using probabilistic-based frequency ratio model. Geocarto Int. 2014, 29, 639-662. [CrossRef]

49. Fawcett, T. An introduction to ROC analysis. Pattern Recognit. Lett. 2006, 27, 861-874. [CrossRef]

50. Friedman, J.; Hastie, T.; Tibshirani, R. Additive logistic regression: A statistical view of boosting (with discussion and a rejoinder by the authors). Ann. Stat. 2000, 28, 337-407. [CrossRef]

51. Quinlan, J.R. C4. 5: Programs for Machine Learning; Elsevier: Amsterdam, The Netherlands, 2014; ISBN 0080500587.

52. Landwehr, N.; Hall, M.; Frank, E. Logistic Model Trees. Mach. Learn. 2005, 59, 161-205. [CrossRef]

53. Lim, T.-S.; Loh, W.-Y.; Shih, Y.-S. A Comparison of Prediction Accuracy, Complexity, and Training Time of Thirty-Three Old and New Classification Algorithms. Mach. Learn. 2000, 40, 203-228. [CrossRef]

54. Shahabi, H.; Ahmad, B.B.; Khezri, S. Evaluation and comparison of bivariate and multivariate statistical methods for landslide susceptibility mapping (case study: Zab basin). Arab. J. Geosci. 2013, 6, 3885-3907. [CrossRef]

55. Doetsch, P.; Buck, C.; Golik, P.; Hoppe, N.; Kramp, M.; Laudenberg, J.; Oberdörfer, C.; Steingrube, P.; Forster, J.; Mauser, A. Logistic model trees with auc split criterion for the kdd cup 2009 small challenge. In Proceedings of the KDD-Cup 2009 Competition. PMLR Proc. Mach. Learn. Res. 2009, 7, 77-88.

56. McFadden, D. Conditional logit analysis of qualitative choice behavior. In Frontiers in Econometrics; Academic Press: Cambridge, MA, USA, 1973.

57. Kleinbaum, D.G.; Klein, M. Survival Analysis; Springer: New York, NY, USA, 2010; ISBN 1441966455. 
58. Colkesen, I.; Sahin, E.K.; Kavzoglu, T. Susceptibility mapping of shallow landslides using kernel-based Gaussian process, support vector machines and logistic regression. J. Afr. Earth Sci. 2016, 118, 53-64. [CrossRef]

59. Lee, S. Application of logistic regression model and its validation for landslide susceptibility mapping using GIS and remote sensing data. Int. J. Remote Sens. 2005, 26, 1477-1491. [CrossRef]

60. Wang, L.-J.; Guo, M.; Sawada, K.; Lin, J.; Zhang, J. A comparative study of landslide susceptibility maps using logistic regression, frequency ratio, decision tree, weights of evidence and artificial neural network. Geosci. J. 2016, 20, 117-136. [CrossRef]

61. Bui, D.T.; Pradhan, B.; Lofman, O.; Revhaug, I.; Dick, O.B. Landslide susceptibility assessment in the Hoa Binh province of Vietnam: A comparison of the Levenberg-Marquardt and Bayesian regularized neural networks. Geomorphology 2012, 171, 12-29.

62. Xu, C.; Xu, X.; Dai, F.; Saraf, A.K. Comparison of different models for susceptibility mapping of earthquake triggered landslides related with the 2008 Wenchuan earthquake in China. Comput. Geosci. 2012, 46, 317-329. [CrossRef]

63. Han, M. The 6th Day of the Earthquake ... Gyeongju Citizens "Continuously Anxious over Aftershocks". Available online: https: / / www.yna.co.kr/view/AKR20160917017800053 (accessed on 21 January 2021).

64. Gliem, J.A.; Gliem, R.R. Calculating, Interpreting, and Reporting Cronbach's Alpha Reliability Coefficient for Likert-Type Scales. In Midwest Rest to Practice Conference in Adult Continuing and Community Education; The Ohio State University: $\mathrm{Colombus,} \mathrm{OH}$ USA, 2003; p. 87.

65. Becker, J.S.; Paton, D.; Johnston, D.M.; Ronan, K.R.; McClure, J. The role of prior experience in informing and motivating earthquake preparedness. Int. J. Disaster Risk Reduct. 2017, 22, 179-193. [CrossRef]

66. Paul, B.K.; Bhuiyan, R.H. Urban earthquake hazard: Perceived seismic risk and preparedness in Dhaka City, Bangladesh. Disasters 2010, 34, 337-359. [CrossRef] [PubMed]

67. Tekeli-Yeşil, S.; Dedeoğlu, N.; Tanner, M.; Braun-Fahrlaender, C.; Obrist, B. Individual preparedness and mitigation actions for a predicted earthquake in Istanbul. Disasters 2010, 34, 910-930. [CrossRef] 